\title{
Tratamiento del paludismo pediátrico: Papel de las intervenciones nutricionales
}

\author{
Akoto Kwame Osei ${ }^{a}$ Davidson H. Hamer ${ }^{a, b}$

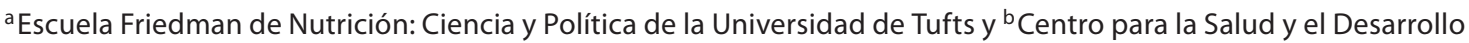 \\ Internacionales, Facultades de Salud Pública y Medicina de la Universidad de Boston, Boston, Mass., EE.UU.
}

\author{
Palabras clave \\ Paludismo, niños, tratamiento - Plasmodium falciparum - Cinc • \\ Hierro • Vitamina A
}

\section{Resumen}

El paludismo es una causa primordial de morbilidad y mortalidad en niños, particularmente en África subsahariana. Aunque se ha logrado un progreso considerable en el tratamiento del paludismo pediátrico con el tratamiento de combinación basado en la artemisinina, siguen existiendo numerosos obstáculos que se oponen a la puesta en práctica efectiva de estas nuevas opciones terapéuticas sumamente eficaces. Análogamente, si bien se dispone de herramientas efectivas para la prevención del paludismo en niños, la ampliación de la escala de éstas para obtener un impacto evidente sobre la morbilidad y la mortalidad asociadas al paludismo ha presentado retos significativos para los funcionarios de salud pública. El estado nutricional del hospedador influye sobre la adquisición y la gravedad potencial de la infección de paludismo. Si bien existen pruebas sustanciales de que el paludismo contribuye a deteriorar la ganancia de peso y talla en niños, el impacto de la subnutrición sobre el paludismo es complejo. Se dispone cada vez de más datos a favor de que el aporte complementario de ciertos micronutrientes puede desempeñar un papel crucial en la prevención del paludismo en niños pequeños. Las intervenciones con micronutrientes, como el aporte complementario de cinc o vitamina $A$, puede contribuir a reducir la carga patológica causada por el paludismo, mientras que otros elementos como el hierro pueden exacerbar la infección. Diferencias en el diseño de los estudios, la calidad, la intensidad de la transmisión del paludismo y otras características que dependen del lugar del estudio complican la interpretación del número limitado de estudios en los que se ha evaluado el impacto de micronutrientes específicos en el tratamiento y la prevención del paludismo. Sólo se realizó un ensayo para evaluar el uso del cinc como coadyuvante en el tratamiento del paludismo, y en éste no se ha podido demostrar ningún beneficio del cinc. En este artículo revisamos el tratamiento clínico del paludismo en niños, las interacciones entre el paludismo y el estado nutricional y el papel potencial del aporte complementario de micronutrientes para la prevención de episodios de paludismo clínico en niños pequeños, con atención particular a si el aporte complementario de cada nutriente mejora o empeora el desenlace del paludismo. Copyright $\odot 2008$ Nestec Ltd., Vevey/S. Karger AG, Basel

\section{Introducción}

Aproximadamente dos mil millones de personas, alrededor de $1 / 3$ de la población mundial, habitan en regiones endémicas de paludismo [1]. El paludismo es una causa primordial de morbilidad y mortalidad para muchas de estas personas, e impone una considerable carga económica y social sobre estas sociedades, particularmente en África subsahariana. De las cuatro especies de Plasmodia que causan la enfermedad humana, Plasmodium falciparum causa la mayor carga de enfermedad y muerte en todo el mundo.

A pesar de la ausencia de datos precisos, la mayoría de las estimaciones concuerdan en que el paludismo causa 800.000 a 1.000 .000 de muertes por año [2, 3]. La proporción de muertes infantiles causadas por el paludismo parece haber aumentado durante las tres últimas décadas [4]. Entre los factores que contribuyen a la elevada carga de mortalidad por paludismo en África destacan el mantenimiento de la confianza en la cloroquina (CQ) a pesar de las elevadas tasas de fallos terapéuticos [5-7], la presencia generalizada de vectores muy competentes

\section{KARGER}

Fax +41613061234 E-Mail karger@karger.ch www.karger.com (c) 2008 Nestec Ltd., Vevey/S. Karger AG, Basel 0252-8185/08/0661-0031\$24.50/0

Accesible online en: www.karger.com/ans
Davidson H. Hamer, MD, FACP

Center for International Health and Development

3rd Floor, Crosstown, 715 Albany Street

Boston, MA 02118 (USA)

Tel. +1 617414 1267, Fax +1 617414 1261, E-Mail dhamer@bu.edu 
en el complejo de Anopheles gambiae [8] y el acceso limitado a una atención médica efectiva.

En un modelo global de carga de paludismo se estimó que 2,2 mil millones de personas presentaban riesgo de infectarse por $P$. falciparum en 2002 y que esta especie era responsable de más de 500 millones de episodios de paludismo clínico [9]. Los niños pequeños y las mujeres gestantes son especialmente vulnerables al paludismo. Se estima que aparecen cada año 400 a 900 millones de episodios de fiebre en niños que habitan en África subsahariana, de los que es probable que aproximadamente la mitad estén causados por el paludismo [8,10-12]. Más del $75 \%$ de estos episodios aparecen en niños menores de 5 años. Entre los efectos indirectos de la pesada carga de paludismo en niños africanos destacan la anemia crónica, el retraso del crecimiento y el retraso del desarrollo cognitivo. A pesar de sufrir ataques clínicos múltiples de paludismo cada año, sólo del 1 al $2 \%$ de los niños pequeños presentan paludismo grave [8]. Los niños que sobreviven al paludismo grave presentan un mayor riesgo de sordera permanente, retraso mental y otras secuelas serias de paludismo cerebral; además, los niños con anemia suficientemente grave para necesitar transfusiones presentan un elevado riesgo de contraer infecciones víricas de transmisión hemática, incluyendo el virus de la inmunodeficiencia humana (VIH).

La infección por $P$. falciparum durante el embarazo incrementa las probabilidades de muerte fetal, prematuridad, retraso del crecimiento intrauterino, bajo peso al nacer y anemia materna [13]. En África subsahariana se estima que el paludismo en el embarazo contribuye a alrededor del 19\% de casos de bajo peso al nacer, más del $20 \%$ de muertes maternas cada año y de 75.000 a 200.000 muertes de lactantes [13-15]. Esta situación ha sido exacerbada por la epidemia de VIH, dado que las mujeres VIH seropositivas presentan un mayor riesgo de complicaciones de paludismo durante el curso de la gestación [16, 17].

Aunque la carga social y económica atribuible al paludismo no se conoce a ciencia cierta, se cree que es considerable. El paludismo es responsable de hasta 45 millones de años de vida ajustados por discapacidad anualmente en toda África [18]. En términos económicos, el paludismo puede costar entre el 0,25 y el 1,3\% de la tasa de crecimiento del producto nacional bruto (PNB) por persona de un país [19, 20]. Entre los costes indirectos del paludismo para la sociedad destacan el rendimiento educacional deficiente de los niños, y la exacerbación de la desnutrición y la anemia, que ejerce un impacto negativo sobre la capacidad cognitiva y física, tanto de niños como de adultos. En consecuencia, es probable que las intervenciones efectivas a favor de la prevención y la mejora del diagnóstico y el tratamiento del paludismo generen beneficios significativos a las poblaciones afectadas, a través del alivio del sufrimiento, la disminución de la mortalidad y la reducción de la carga socioeconómica de la enfermedad causada por esta infección parasitaria generalizada. Se dispone cada vez de más pruebas de que ciertas intervenciones simples con micronutrientes pue- den contribuir a reducir la carga de mortalidad debida al paludismo en niños pequeños, mientras que otras, especialmente con hierro, pueden exacerbar la enfermedad.

\section{Manifestaciones clínicas del paludismo en niños}

Los síntomas de paludismo suelen aparecer al cabo de unos 10 a 15 días tras la picadura de un mosquito infectado. Entre los síntomas prodrómicos pueden aparecer malestar, fatiga, mialgias, artralgias, cefalea, anorexia, y fiebre de baja intensidad [21]. Pueden durar 2 a 3 días antes de que aparezca un paroxismo agudo. Un ataque agudo comienza con escalofrío o rigidez y, seguidamente, en el curso de 30 a 60 minutos, aparece fiebre asociada a taquicardia, sudoración profusa, cefalea, malestar y mialgias. Los pacientes pueden presentar también nausea, vómito, diarrea leve, dolor abdominal, enrojecimiento de la piel y piel seca. Las fiebres elevadas duran varias horas y, a continuación, se siguen de un periodo de sudoración intensa. A medida que progresan las infecciones no tratadas, el bazo se agranda gradualmente y la anemia empeora. También pueden aparecer hepatomegalia, hipotensión ortostática, confusión mental e ictericia. Entre los signos de laboratorio adicionales destacan trombocitopenia, leucopenia y proteinuria. Pueden aparecer anomalías en las pruebas de función hepática, con elevaciones de las transaminasas en el suero, hiperbilirrubinemia, hipoalbuminemia y prolongación del tiempo de protrombina.

\section{Paludismo grave}

El paludismo grave aparece fundamentalmente en niños infectados por P. falciparum; son raras las ocasiones en las que se debe a $P$. vivax. En las regiones del mundo donde la fiebre terciana maligna es endémica, el paludismo grave es predominantemente una enfermedad que afecta a niños pequeños desde los primerísimos meses de vida, cuando se desvanece la inmunidad materna adquirida pasivamente, hasta los cinco o más años de edad, en función de la intensidad local de la transmisión. Entre las manifestaciones clínicas y de laboratorio comunes del paludismo grave en niños destacan postración, deterioro de la conciencia, disnea, convulsiones recurrentes, anemia grave (hemoglobina $<5 \mathrm{~g} / \mathrm{dl}$ o hematocrito $<15 \%$ ), hipoglucemia, acidosis metabólica y, con menos frecuencia, colapso circulatorio [22]. Entre las manifestaciones adicionales que aparecen algo menos frecuentemente en los niños que en los adultos mencionaremos las siguientes: hemoglobinuria, sangrado anormal, ictericia y edema pulmonar. El paludismo cerebral, una de las manifestaciones más corrientes y amenazadoras de la vida de la fiebre terciana maligna, consiste en trastornos de la conciencia (desde confusión, delirio y estupor hasta coma), convulsiones, anomalías del tono muscular, hemorragias retinianas y deficiencias neurológicas focales. Debe indagarse la eventual presencia de hipoglucemia. Las tasas de letalidad del 10 al 20\% son corrientes. Los supervivientes pueden presentar secuelas neurológicas a largo plazo. 
Entre las características clínicas y de laboratorio, asociadas a un mayor riesgo de fallecimiento en niños con paludismo grave, destacan las siguientes: hipoglucemia, profundidad del coma, crisis confirmadas, disnea, acidosis o incremento de las concentraciones plasmáticas de lactato, ictericia, elevación de la concentración de lactato en el líquido cefalorraquídeo, papiledema, edema retiniano, más del $20 \%$ de parásitos en una película de sangre periférica que contiene pigmento palúdico y concentraciones considerablemente superiores del factor de necrosis tumoral $[22,23]$. En un estudio reciente realizado en Ghana en niños con paludismo grave, con una tasa global de letalidad del $11,2 \%$, se encontró que el colapso circulatorio, el deterioro de la conciencia, la hipoglucemia y la desnutrición pronosticaban la muerte de forma independiente [24]. En el estudio de Ghana, aunque la anemia grave fue la manifestación más corriente, no se asociaba a un incremento del riesgo de mortalidad. Mientras que estos factores pronósticos de paludismo fueron identificados predominantemente en estudios en niños africanos con paludismo grave, en un estudio prospectivo realizado recientemente en Orissa, India, se hallaron factores pronósticos algo diferentes de mortalidad infantil, incluyendo disnea, coma, disfunciones multiorgánicas (afectación de $\geq 2$ sistemas orgánicos) e hiperparasitemia [25].

\section{Interacciones entre paludismo y nutrición}

La interacción entre paludismo y nutrición es compleja [26] y ha sido objeto de debate desde comienzos de la década de los 50. Varios estudios han registrado asociaciones entre paludismo y desnutrición de proteína y energía, retraso del crecimiento y ciertas carencias de micronutrientes en niños [27-30]. Por otra parte, estudios de prevención del paludismo, por medio de mosquiteros para las camas tratados con insecticida o quimioprofilaxis, se han asociado con la mejora del crecimiento y el estado de micronutrientes de los niños [31-34].

A pesar de las pruebas evidentes del impacto que ejerce el paludismo sobre la situación nutricional de los individuos afectados, el efecto de la situación nutricional sobre la resistencia del hospedador a la adquisición y progresión del paludismo no está claramente definido todavía. Tiene un interés particular conocer si la subnutrición aumenta en algunos individuos el riesgo de contraer el paludismo o presentar infecciones más graves.

\section{La desnutrición proteico-energética y el paludismo}

En estudios preliminares se ha dado a entender que sujetos deficientemente alimentados quedaban en alguna medida protegidos frente al paludismo [35-40]. Hendrickse y cols. [37] hallaron que pacientes con paludismo clínico, caracterizado por una parasitemia de densidad elevada, tenían más probabilidad de situarse por encima del percentil 10 de peso para la edad que aquéllos con una parasitemia de baja densidad. Ahmad y cols. [41] mostraron una correlación positiva entre el nivel de parasitemia y el peso para la edad en niños infectados por P. falciparum o P. vivax. Murray y cols. [35] demostraron que la alimentación de víctimas de hambruna por desnutrición resultaba en un incremento de la aparición de ataques de paludismo clínico, incluyendo más complicaciones cerebrales. En un estudio realizado por Olumese y cols. [42] en Nigeria, también se hallaron peores resultados en niños desnutridos que estaban siendo tratados por paludismo cerebral. En un estudio más reciente, realizado en Papúa-Nueva Guinea, el impedimento del crecimiento parecía disminuir el riesgo de presentación de fiebre terciana maligna [43]. De este modo, estos estudios dan a entender que la subnutrición, especialmente la desnutrición de proteína y energía, contribuye a proteger contra el paludismo.

No obstante, en otros estudios se han obtenido resultados contrarios. Utilizando un diseño transversal, el Samani y cols. [44] registraron la presencia de paludismo más frecuentemente en niños sudaneses malnutridos que en los alimentados adecuadamente. Los estudios transversales de Tanzania [45], Chad [46], Zaire [47] y Kenia [30] confirman el mayor riesgo de paludismo en niños con un estado nutricional deficiente. Un estudio longitudinal de Vanuatu [48] apoya la afirmación de que la desnutrición predispone al hospedador a la infección de paludismo, aunque en otro estudio prospectivo de Gambia no se hallaron prácticamente asociaciones entre el estado nutricional y la propensión al paludismo [49].

En una revisión más reciente de la literatura sobre paludismo y nutrición [50] se llegó a la conclusión de que los datos preliminares de un efecto protector de la desnutrición frente al paludismo se basaron principalmente en estudios con varios fallos metodológicos. La reevaluación de los datos, conjuntamente con la literatura reciente, indica que el efecto de la nutrición sobre la propensión del hospedador al paludismo es más complejo y que, en numerosos casos, un estado nutricional deficiente predispone al hospedador a un mayor riesgo de infección, ataques de paludismo clínico sintomático y a una mayor probabilidad de mortalidad causada por el paludismo.

\section{Diagnóstico}

El diagnóstico definitivo del paludismo depende de la identificación del parásito en frotes de sangre teñidas con Giemsa. Deben evaluarse frotes tanto gruesos como finos. Los frotes gruesos son más sensibles para la detección del parásito, pero no son útiles para la identificación de la especie. Si los frotes iniciales son negativos pero hay una fuerte sospecha clínica de paludismo, deben repetirse en 6 horas.

Para la detección de $P$. falciparum se han elaborado las más recientes pruebas inmunocromatográficas rápidas, que utilizan anticuerpos y reconocen la proteína rica en histidina o la lactatodeshidrogenasa parasitaria. Estas pruebas son de ejecución más sencilla y tienen sensibilidades del 90 al 95\% en comparación con los frotes de sangre; sin embargo, tienden a ser 
relativamente insensibles si la densidad del parásito es baja (por ejemplo, $<100$ formas asexuadas/ $\mu l$ ) $[51,52]$.

En numerosas zonas rurales de África subsahariana y otras regiones del mundo endémicas de paludismo, las pruebas diagnósticas no están disponibles. Las normas del Tratamiento Integrado de Enfermedades Infantiles (IMCI) de la Organización Mundial de la Salud (OMS) recomiendan el tratamiento de todas las fiebres en niños menores de 5 años con medicación antipalúdica en países con paludismo endémico [53]. Con arreglo al IMCI, en regiones con riesgo elevado de paludismo cualquier niño con fiebre o antecedentes de fiebre en ausencia de signos de paludismo grave es sospechoso de presentar paludismo no complicado.

\section{Problemas diagnósticos en el tratamiento de casos} pediátricos

Un problema muy importante en el tratamiento de casos de paludismo infantil es el diagnóstico excesivo y el tratamiento excesivo de enfermedades inespecíficas como el paludismo $[54,55]$. Dado que la mayoría de los servicios clínicos rurales carecen de instalaciones de laboratorio para realizar frotes, la decisión de tratar el paludismo se basa habitualmente en datos clínicos. Además, las infecciones agudas de las vías respiratorias inferiores pueden ser clasificadas fácil y erróneamente como paludismo de acuerdo a la guía actual del IMCI [56]. El tratamiento provisional es menos aceptable ya que el coste de nuevos tratamientos, como la terapéutica de combinación (basada en artemisinina, TCA), es considerablemente superior al de tratamientos menos eficaces, como la CQ. Los nuevos diagnósticos, como las pruebas rápidas de antígenos, ofrecen un medio potencial que permite a los profesionales sanitarios establecer un diagnóstico de paludismo más rápido y más exacto $[51,57]$.

Con la disponibilidad de las pruebas diagnósticas rápidas es posible que los resultados del tratamiento de los casos puedan alcanzarse a un menor costo gracias al empleo de estas pruebas altamente específicas para mejorar la selección de los costosos fármacos de los tratamientos de combinación. No obstante, en estudios recientes se deja entrever que esta herramienta diagnóstica relativamente nueva no se está utilizando eficazmente, dado que del 30 al 50\% de los niños con pruebas diagnósticas rápidas negativas están recibiendo todavía tratamiento con antipalúdicos y una proporción considerable no es analizada a pesar de la disponibilidad de las pruebas $[58,59]$.

\section{Tratamiento del paludismo pediátrico}

Varios factores influyen sobre las decisiones terapéuticas del paludismo. Entre éstos destacan la gravedad de la infección, la edad del niño, el grado de la inmunidad de fondo, otros factores del hospedador que puedan deteriorar la función inmunitaria, como la desnutrición o la infección por VIH avanzada, características locales de resistencia a fármacos antipa- lúdicos, disponibilidad de fármacos y coste de los fármacos antipalúdicos [60]. El objetivo del tratamiento en niños con paludismo no complicado debe ser curar la infección, es decir, erradicar por completo el parásito del organismo, de manera que no exista la posibilidad de un recrudecimiento de la infección [21].

La piedra angular de los esfuerzos coordinados del Roll Back Malaria Program en África ha sido la mejora del tratamiento de los casos de paludismo [61]. Los partidarios del Roll Back Malaria dan a entender que dicho tratamiento de casos considerablemente fortalecido podría reducir la mortalidad del paludismo a la mitad en el año 2010. El éxito del fortalecimiento del tratamiento de casos de paludismo depende del progreso en cuatro ámbitos: (1) tratamiento eficaz; (2) diagnóstico exacto y confiable; (3) disponibilidad de fármacos; (4) identificación de la enfermedad y utilización apropiada de los fármacos a nivel de vivienda y comunidad. Desafortunadamente, en cada uno de estos ámbitos existen brechas sustanciales en el conocimiento y la aplicación.

\section{Resistencia a fármacos antipalúdicos}

La eficacia clínica de la CQ ha declinado durante las tres últimas décadas en una gran parte de África oriental y meridional [62]. Los niños presentan un mayor riesgo de fallo del tratamiento con CQ; los resultados de un estudio multinacional de paludismo revelaron que la poca edad, la temperatura inicial más elevada y la mayor parasitemia basal pronosticaban un fracaso temprano del tratamiento y una mayor probabilidad de empeoramiento de la anemia entre el ingreso y 7 ó 14 días después del tratamiento [63]. Debido a las crecientes pruebas de la eficacia declinante de la CQ, en varios países se sustituyó este fármaco por la sulfadoxina-pirimetamina (SP) como medicamento antipalúdico de primera línea. Es preocupante que en muchos de estos países la eficacia clínica de la SP declinara rápidamente [64] obligando en varios de ellos a cambiar sus políticas nacionales, sustituyendo SP por TCA.

Actualmente existe un acuerdo general sobre las combinaciones de agentes antipalúdicos eficaces que deben utilizarse $[21,65,66]$. La OMS ha recomendado que la TCA debe ser el sustituto preferido en los fallos de las monoterapias [21]. Para el tratamiento del paludismo infantil en África subsahariana se han evaluado varias opciones terapéuticas diferentes, incluyendo la combinación de dosis fijas, Coartem ${ }^{\circledR}$ (artemeter-lumefantrina), una combinación en un mismo envase de amodiaquina y artesunato, y SP más artesunato. En algunas partes de Âfrica y en otras regiones, especialmente en Asia sudoriental, el tratamiento de elección es mefloquina más artesunato. Ambos han demostrado su considerable eficacia en ensayos clínicos de fase III, en áreas con niveles moderados a elevados de resistencia a SP o CQ en África y Tailandia [67-69]. A pesar de su eficacia en estudios de investigación, la complejidad de sus pautas de aplicación deja sin confirmar la eficacia de la TCA como tratamiento de primera línea. Por otra parte, la TCA es significativamente más costosa que la CQ o la SP. 
Problemas en la instauración de la TCA para el paludismo pediátrico no complicado

La instauración del tratamiento de casos eficaz con TCA afronta un cierto número de problemas, en particular, complejos procedimientos de pedidos y financiación, la necesidad de formar a técnicos sanitarios y proporcionar normas claras para su empleo, así como su introducción en sistemas sanitarios débiles, caracterizados corrientemente por procedimientos subóptimos de manejo de fármacos y prácticas clínicas [70, 71]. En consecuencia, a pesar de su carácter prometedor, los nuevos fármacos de la TCA podrían no llegar a los pacientes que los precisasen y, en caso que si les llegasen, se mantendría el reto de garantizar procedimientos clínicos adecuados. En varios estudios recientes, en los que se examinó el uso operativo de las TCA tras un cambio en la política nacional en Kenia y Zambia, se han identificado deficiencias serias en la disponibilidad de los fármacos de la TCA y la idoneidad de su empleo por parte de los profesionales sanitarios [72-74]. Los resultados de estos estudios dejan entrever que los cambios en los procedimientos clínicos en el lugar asistencial tardarán más de lo previsto en instaurarse. Entre los problemas principales destaca la necesidad de asegurar un suministro constante, ininterrumpido, de los fármacos a los centros de salud, actividades programáticas encaminadas a retirar los medicamentos ineficaces, formar técnicos sanitarios en las nuevas normas, proporcionar un incremento de la supervisión y monitorizar constantemente las ambigüedades y los mensajes ocultos en las normas que afectan a la prescripción correcta. También existe una necesidad urgente de evaluar nuevos abordajes, potencialmente menos costosos y más eficaces, para cambiar el procedimiento clínico de los profesionales sanitarios en la periferia del sistema sanitario.

\section{Recomendaciones terapéuticas específicas para el}

paludismo pediátrico

Después de establecer un diagnóstico específico de la especie, las elecciones terapéuticas deberán basarse en los patrones locales de resistencia y dependerán de qué fármacos antipalúdicos están disponibles localmente. Los niños infectados por $P$. vivax, P. ovale o P. malariae deben ser tratados con CQ (tabla 1). Con la excepción de ciertas partes de Asia sudoriental, donde se ha descrito resistencia a la CQ [75], este fármaco sigue siendo eficaz para el tratamiento de estas tres especies. También debe suministrarse un ciclo de dos semanas de primaquina, después de asegurarse de que el niño no presenta deficiencia de glucosa-6-fosfato deshidrogenasa, para erradicar hipnozoitos del hígado con objeto de evitar recidivas.

La CQ sigue siendo eficaz para el tratamiento de P. falciparum en América Central, México, Haití, República Dominicana y regiones de Oriente medio, donde el paludismo es endémico. No obstante, en una gran parte del mundo la resistencia a la CQ y la SP se ha generalizado, de manera que debe utilizarse TCA, quinina o mefloquina. Aunque la combinación artemeter-lumefantrina se utilizó al principio fundamentalmen- te en niños que pesaban $>10 \mathrm{~kg}$, en un estudio multicéntrico reciente en África se da a entender que es segura y eficaz en niños con pesos comprendidos entre 5 y $10 \mathrm{~kg}$ [76]. Los niños con fiebre, especialmente $\geq 38,5^{\circ} \mathrm{C}$, deben tratarse con fármacos antipiréticos para evitar la aparición de convulsiones febriles. Aunque en algunos estudios se deja entrever que el uso de paracetamol propició una prolongación de la parasitemia, la OMS recomienda actualmente su utilización en el tratamiento de niños febriles con paludismo [21]. Basándose en un número limitado de estudios sobre el efecto de la malnutrición subyacente sobre la CQ, la SP, la doxiciclina y la quinina, no parece existir necesidad alguna de ajustar sus dosis en niños desnutridos. Análogamente, hasta la fecha no se dispone de datos en niños de bajo peso o caquécticos con respecto a ninguna de las TCA más recientes, de manera que deben administrarse las mismas dosis que en niños bien nutridos.

\section{Papel del cinc como coadyuvante del tratamiento del paludismo}

Basándose en resultados de estudios de diarrea y neumonía, que revelaron efectos beneficiosos del cinc para reducir la duración de la enfermedad, se ha evaluado el uso del cinc como coadyuvante del tratamiento de la fiebre terciana maligna aguda, no complicada, en niños pequeños, en un ensayo multicéntrico, aleatorizado, controlado con placebo, realizado en Ecuador, Ghana, Tanzania, Uganda y Zambia [77]. En estos países se incluyó a niños $(\mathrm{n}=1.087)$, de edades comprendidas entre 6 meses y 5 años, con fiebre y $\geq 2.000 / \mu l$ formas asexuadas de $P$. falciparum en un frote hemático grueso, y se les administró aleatoriamente cinc ( $20 \mathrm{mg} /$ día en lactantes, $40 \mathrm{mg} / \mathrm{día}$ en niños mayores) o placebo durante 4 días, así como CQ, el tratamiento antipalúdico estándar de primera línea en todos estos países, en el momento de iniciar el estudio. No se observaron efectos del cinc sobre la mediana del tiempo hasta la reducción de la fiebre ( $\operatorname{cinc}=24,2 \mathrm{~h}$ frente a placebo $=24,0 \mathrm{~h} ; \mathrm{p}=0,37)$, la reducción de la parasitemia en $>75 \%$ en las 72 primeras horas (grupo cinc $=73,4 \%$; grupo placebo $=77,6 \% ; p=0,11$ ) ni la concentración de hemoglobina durante el periodo de 3 días de hospitalización o el periodo de seguimiento de 4 semanas. Aunque en este estudio no fue posible demostrar un efecto beneficioso del cinc como coadyuvante del tratamiento del paludismo, reveló claramente el impacto de la inflamación causada por la respuesta de fase aguda inducida por el paludismo sobre las concentraciones plasmáticas de cinc. Se registró una asociación significativa inversa entre la densidad de la parasitemia y la concentración plasmática de cinc [78]. El tratamiento satisfactorio del paludismo se asoció a una elevación significativa de los niveles plasmáticos de cinc incluso en ausencia de un aporte complementario concomitante de cinc.

\section{Tratamiento del paludismo grave}

El objetivo principal del tratamiento de niños con paludismo grave es evitar su muerte. Debido a que el fallecimiento puede acontecer en el transcurso de las horas para llegar a a un 
Tabla 1. Opciones terapéuticas para el paludismo pediátrico

\begin{tabular}{|c|c|c|c|}
\hline Tipo de paludismo & \multicolumn{2}{|l|}{ Fármaco $^{1}$} & Comentarios \\
\hline \multicolumn{4}{|l|}{ No complicado ${ }^{2}$} \\
\hline P. malariae & \multicolumn{3}{|l|}{ Cloroquina } \\
\hline P. falciparum sensible a cloroquina & \multicolumn{2}{|l|}{ Cloroquina } & $\begin{array}{l}\text { Cepas halladas en América Central, } \\
\text { México, República Dominicana y Haití } \\
\text { y Oriente Medio }\end{array}$ \\
\hline$P$. vivax resistente a cloroquina & \multicolumn{2}{|c|}{$\begin{array}{l}\text { Sulfato de quinina más doxiciclina }{ }^{4} \\
\text { o mefloquina }\end{array}$} & $\begin{array}{l}\text { Cepas halladas en varios países de Asia } \\
\text { sudoriental, Oceanía y América del Sur }\end{array}$ \\
\hline P. falciparum resistente a cloroquina & \multicolumn{2}{|c|}{$\begin{array}{l}\text { Artemeter - lumefantrina } \\
\text { Artesunato más amodiaquina } \\
\text { Artesunato más mefloquina } \\
\text { Artesunato más sulfadoxina - pirimetamina } \\
\text { Quinina oral más doxiciclina }{ }^{4} \\
\text { Atovacuona - proguanil }\end{array}$} & Tailandia RR \\
\hline $\begin{array}{l}\text { Grave }{ }^{2} \\
P . \text { falciparum sensible a cloroquina } \\
\quad \text { o resistente a cloroquina }\end{array}$ & \multicolumn{2}{|l|}{$\begin{array}{l}\text { Quinina i.v. o i.m. } 5,6 \\
\text { Artesunato i.v. o i.m } \\
\text { Artemeter i.m. }\end{array}$} & $\begin{array}{l}\text { Ya no se recomienda cloroquina } \\
\text { parenteral }\end{array}$ \\
\hline \multicolumn{2}{|c|}{$\begin{array}{l}{ }^{1} \text { Las normas de administración específicas y las contraindica- } \\
\text { ciones están disponibles en las normas terapéuticas de la OMS y } \\
\text { la Guía Sanford de Tratamiento Antimicrobiano }[21,153] \text {. } \\
{ }^{2} \text { El control de la fiebre es importante para contribuir a reducir } \\
\text { el riesgo de convulsiones febriles en niños. Debe administrarse } \\
\text { paracetamol o ibuprofeno en niños con temperaturas } \geq 38,5^{\circ} \mathrm{C} \text {. } \\
{ }^{3} \text { Es necesario indagar la deficiencia de glucosa- } 6 \text {-fosfato des- } \\
\text { hidrogenasa. }\end{array}$} & $\begin{array}{l}{ }^{4} \text { El uso debe evi } \\
\text { tituirse por clindan } \\
\text { nina. } \\
{ }^{5} \text { Se prefiere la } \\
\text { (i.m.) debido a la ab } \\
\text { con paludismo grav } \\
{ }^{6} \text { Si no se dispo } \\
\text { dina. }\end{array}$ & $\begin{array}{l}\text { en niños menores de } 8 \text { años. Puede sus- } \\
\text { a como coadyuvante del sulfato de qui- } \\
\text { ina intravenosa (i.v.) a la intramuscular } \\
\text { ión potencialmente errática en pacientes } \\
\text { hock. } \\
\text { le quinina puede sustituirse por quini- }\end{array}$ \\
\hline
\end{tabular}

centro de salud, el tratamiento inicial debe ser apropiado y agresivo para asegurar que se alcanzan rápidamente las concentraciones terapéuticas antipalúdicas. En otros trabajos puede hallarse información detallada sobre el tratamiento del paludismo grave [21, 22]. El balance hidroelectrolítico debe ser evaluado y abordado rápidamente. Las opciones terapéuticas se enumeran en la tabla 1. En uno de los estudios comparativos más extensos se comprobó que el tratamiento con artesunato parenteral se asociaba a una reducción de la mortalidad del $37 \%$ en comparación con quinina [79]. El artemeter intramuscular es una alternativa adicional a la quinina. En ámbitos donde el tratamiento parenteral no está disponible, el uso de supositorios rectales de artesunato puede salvar vidas [21, 80]. El artesunato rectal es también útil como puente al tratamiento oral en niños con paludismo no complicado, que inicialmente son incapaces de ingerir medicaciones por vía oral.

Medidas de apoyo en el tratamiento del paludismo grave

Las medidas coadyuvantes desempeñan un papel importante en el tratamiento de niños con paludismo grave. La des- hidratación es corriente en los niños y debe ser abordada de forma rápida, pero juiciosa, con objeto de evitar la insuficiencia renal aguda debida a necrosis tubular aguda [60]. En los niños con coma, secundaria al paludismo cerebral, deben evaluarse otras causas potencialmente tratables de alteración del sistema nervioso central, como hipoglucemia y meningitis bacteriana. Estos pacientes precisan también un manejo de las vías respiratorias para evitar la aspiración. Las convulsiones deben ser tratadas de inmediato con benzodiacepinas o paraldehido por vía intravenosa; si el acceso intravenoso no está disponible, el diacepam rectal es una alternativa $[22,60]$. No está confirmada la utilidad de un tratamiento auxiliar con heparina, ciclosporina o corticosteroides.

La fiebre debe ser tratada con medidas mecánicas, como enjuagues tibios con una esponja, el uso de un ventilador o una manta refrigerante, así como antipiréticos como paracetamol. Debe monitorizarse la glucosa en sangre y tratar rápidamente la hipoglucemia. El mantenimiento de los fluidos con un líquido glucosado contribuye a reducir el riesgo de hipoglucemia. La anemia grave, especialmente en niños con trastorno respi- 
ratorio concomitante, debe abordarse por medio de transfusión con sangre entera fresca o concentrado de eritrocitos, después de excluir adecuadamente la presencia de patógenos transmitidos por vía hemática. Dado que puede aparecer bacteriemia en el 5 al 8\% de los niños con paludismo grave [81], la obtención de hemocultivos y el tratamiento de la septicemia con antibióticos apropiados es de importancia vital, especialmente en los niños con shock o acidosis metabólica. Los pacientes con coagulación intravascular diseminada deben recibir vitamina $\mathrm{K}$ y transfusiones con sangre fresca y comprobada.

Si la duración del coma se prolonga, es decir, durante más de tres días, existe un mayor riesgo de neumonía. Si un niño con paludismo grave empeora súbitamente, debe excluirse la presencia de una hipoglucemia, obtener hemocultivos e iniciar un tratamiento empírico con agentes antimicrobianos de amplio espectro. La densidad parasitaria debe monitorizarse como mínimo dos veces al día, y si el recuento de parásitos no se ha reducido en el 75\% 48 horas después de iniciar el tratamiento, debe considerarse la administración de un agente antipalúdico alternativo.

Se ha realizado un número limitado de estudios para evaluar la farmacocinética de la quinina en niños con desnutrición de proteína y energía; mientras que en uno de ellos se ha dado a entender la necesidad de reducir el intervalo de administración de quinina intramuscular de 12 a 8 horas [82], otros dos estudios de administración oral e intravenosa de quinina, respectivamente, revelaron varias diferencias en la farmacodinámica de la quinina en niños infectados y no infectados de paludismo con desnutrición global grave $[83,84]$. No obstante, los autores de ambos estudios llegaron a la conclusión de que no es necesario modificar las dosis.

\section{Interacciones entre micronutrientes específicos y paludismo}

En la mayoría del número limitado de ensayos clínicos en los que se han evaluado los micronutrientes en niños en regiones endémicas de paludismo, se han incluido ensayos de aportes complementarios para la prevención del paludismo. Además del papel potencial de los micronutrientes, los métodos actuales y potenciales para el control del paludismo incluyen materiales tratados con insecticidas (es decir, redes para camas y cortinas), el control de las larvas de mosquitos, residuos de la pulverización con insecticidas en interiores, vectores genéticamente modificados, vacunas y fármacos perfeccionados para el tratamiento y la prevención de los ataques de paludismo [85]. El desarrollo y los estudios de una vacuna eficaz para el paludismo es una importante prioridad de la investigación, si bien, hasta la fecha, las vacunas eficaces se han mostrado esquivas. En la sección siguiente se ofrecerá una perspectiva general del número limitado de micronutrientes que han sido evaluados más exhaustivamente en relación con el paludismo.

\section{Cinc}

El cinc es un oligoelemento esencial para el crecimiento y la diferenciación celulares $[86,87]$. Debido a su papel crucial en la división celular, la carencia de cinc resulta en un deterioro de la función inmunitaria y en una reducción de la resistencia a las infecciones. Se ha planteado la hipótesis de que la carencia de cinc exacerba la infección de paludismo [87] y cada vez son mayores las pruebas disponibles de que el aporte complementario de cinc podría contribuir a prevenir el paludismo (tabla 2). En un ensayo del aporte complementario de cinc en Gambia se observó una reducción del 32\% de las visitas a los centros de salud por paludismo confirmado por microscopía, si bien esta diferencia no alcanza una significación estadística [88]. Un periodo de 46 semanas de aporte complementario de cinc suministrado a niños preescolares en Papúa-Nueva Guinea redujo significativamente, en un $38 \%$, las visitas a los centros de salud atribuibles a P. falciparum $(\mathrm{p}=0,037)$ [89] (tabla 2). Los episodios de paludismo acompañados de cualquier nivel de parasitemia se redujeron también en un $38 \%(\mathrm{p}=0,028)$ y los episodios con parasitemia $\geq 100.000 / \mu l$ se redujeron en el 69\% ( $p=0,009)$ en dicho estudio. Por el contrario, en una prueba comunitaria realizada en Burkina Faso, en la que se administraron a niños de edades comprendidas entre 6 y 31 meses $12,5 \mathrm{mg}$ de aporte complementario de cinc o placebo durante 6 días por semana en el curso de 6 meses, no se pudo registrar ningún beneficio del cinc sobre la incidencia de episodios de paludismo clínico [90]. No obstante, utilizando datos transversales basales y finales del estudio, la densidad media de los parásitos $P$. falciparum aumentó significativamente ( $p=0,001)$ durante el estudio en el grupo placebo en comparación con el grupo cinc. No se comprende por qué en este estudio la incidencia de episodios clínicos de paludismo no era influida por el cinc. Al contrario que en los estudios de Gambia y Papúa-Nueva Guinea, en los que se utilizaron los episodios de paludismo confirmados como criterio principal de valoración, en el estudio de Burkina Faso se utilizó la vigilancia de las viviendas con respecto a la fiebre como indicador de los episodios de paludismo. Otra posibilidad es que el tamaño de la muestra fuera demasiado reducido para medir este efecto, dado que la proporción de episodios de paludismo febril de todos los niños con frotes hemáticos positivos era bastante escasa. Por último, la prevalencia de deficiencia clínica de cinc en la población en estudio era demasiado baja. Utilizando un valor límite para la deficiencia de cinc de $60 \mu \mathrm{g} / \mathrm{dl}$ [91], sólo una pequeña proporción de estos niños presentaba deficiencia de cinc en situación basal, dado que la concentración media de cinc era de 76,5 $\mu \mathrm{g} / \mathrm{dl}$. Teóricamente, el cinc podría haber producido un mayor efecto sobre la enfermedad clínica si se hubiera utilizado en una población en la que la carencia de cinc fuera generalizada. En contraste con el estudio anterior [90], en un ensayo más reciente en una región diferente de Burkina Faso, en el que se evaluó la combinación de una dosis única elevada de vitamina A y aporte complementario de cinc diario, 
Tabla 2. Ensayos de aporte complementario de micronutrientes y prevención del paludismo

\begin{tabular}{|c|c|c|c|c|c|c|c|c|}
\hline $\begin{array}{l}\text { Muller } \\
\text { y cols. } \\
{[90]} \\
2001\end{array}$ & $\begin{array}{l}\text { Burkina } \\
\text { Faso }\end{array}$ & $\begin{array}{l}\text { Niños } \\
\text { (6 a } 31 \\
\text { meses) }\end{array}$ & 709 & $\begin{array}{l}\text { Ensayo a } \\
\text { doble ciego, } \\
\text { aleatorizado, } \\
\text { controlado } \\
\text { con placebo }\end{array}$ & $\begin{array}{l}\text { Comple- } \\
\text { mento } \\
\text { y placebo }\end{array}$ & $\begin{array}{l}12,5 \mathrm{mg} \text { (como sulfato } \\
\text { de cinc) } 6 \text { días } \\
\text { por semana } \\
\text { durante } 6 \text { meses }\end{array}$ & $\begin{array}{l}\text { Episodios de } \\
\text { paludismo } \\
\text { confirmados } \\
\text { por microscopía }\end{array}$ & $\begin{array}{l}\text { Ausencia de diferencia entre el } \\
\text { grupo cinc y el grupo placebo en } \\
\text { la incidencia de fiebre terciana } \\
\text { maligna (riesgo relativo: } 0,98 \text {; IC } \\
\text { 95\%: } 0,86 \text { a } 1,11 \text { ) }\end{array}$ \\
\hline $\begin{array}{l}\text { Binka } \\
\text { y cols. } \\
{[102]} \\
1995\end{array}$ & Ghana & $\begin{array}{l}\text { Niños } \\
\text { (6 a } 90 \\
\text { meses) }\end{array}$ & 23.361 & $\begin{array}{l}\text { Ensayo a } \\
\text { doble ciego, } \\
\text { aleatorizado, } \\
\text { controlado } \\
\text { con placebo, } \\
\text { en dos centros }\end{array}$ & $\begin{array}{l}\text { Comple- } \\
\text { mento } \\
\text { y placebo }\end{array}$ & $\begin{array}{l}30 \text { mg (niños de } 6 \text { a } 11 \\
\text { meses) y } 60 \text { mg (niños } \\
\text { mayores) de equivalente } \\
\text { de retinol, como palmitato } \\
\text { de retinil en aceite de } \\
\text { cacahuete purificado o } \\
\text { placebo durante } 24 \text { meses }\end{array}$ & $\begin{array}{l}\text { Menos } \\
\text { episodios y } \\
\text { tasa de } \\
\text { mortalidad de } \\
\text { paludismo }\end{array}$ & $\begin{array}{l}\text { Reducción del } 32 \% \text { y } 23 \% \text { de la } \\
\text { probable afección palúdica }\end{array}$ \\
\hline $\begin{array}{l}\text { Shankar } \\
\text { y cols. } \\
\text { [109], } \\
1999\end{array}$ & $\begin{array}{l}\text { Papúa- } \\
\text { Nueva } \\
\text { Guinea }\end{array}$ & $\begin{array}{l}\text { Niños } \\
\text { (6 a } 60 \\
\text { meses) }\end{array}$ & 480 & $\begin{array}{l}\text { Ensayo a } \\
\text { doble ciego, } \\
\text { aleatorizado, } \\
\text { controlado } \\
\text { con placebo }\end{array}$ & $\begin{array}{l}\text { Comple- } \\
\text { mento y } \\
\text { placebo }\end{array}$ & $\begin{array}{l}200.000 \text { UI de } \\
\text { vitamina A } \\
\text { cada } 3 \text { meses } \\
\text { durante } \\
13 \text { meses }\end{array}$ & $\begin{array}{l}\text { Episodios de } \\
\text { paludismo } \\
\text { confirmados } \\
\text { por microscopía }\end{array}$ & $\begin{array}{l}\text { Reducción del } 30 \% \text { de episodios } \\
\text { de paludismo febriles } \\
\text { Reducción del } 36 \% \text { de la } \\
\text { parasitemia } \\
\text { Reducción del } 11 \% \text { de la } \\
\text { esplenomegalia }\end{array}$ \\
\hline
\end{tabular}

se hallaron reducciones significativas de los episodios de paludismo clínico y una prolongación del tiempo hasta el primer episodio de paludismo [92].

En conjunto, los resultados de estos estudios dan a entender que el cinc puede desempeñar un papel importante en la prevención del paludismo en niños pequeños. No obstante, es imprescindible la realización de más investigación para respaldar esta afirmación y determinar los métodos óptimos para suministrar cinc a niños en regiones endémicas de paludismo.

\section{Vitamina A}

La vitamina A desempeña un papel esencial en la división celular, la respuesta inmunitaria, la visión, la reproducción y el estado de salud general de niños [93]. La deficiencia marginal de vitamina $\mathrm{A}$, un proceso corriente en niños en regiones endémicas de paludismo, se ha asociado a un mayor riesgo de morbilidad y mortalidad debidas a una amplia gama de infecciones, incluyendo sarampión, neumonía, diarrea y paludismo [94]. La vitamina A puede contribuir a reducir la morbilidad asociada al paludismo en función de sus efectos beneficiosos sobre la función inmunitaria. Concentraciones de retinol similares a las halladas en el suero humano normal reducían la multiplicación de P. falciparum en uno de los modelos in vitro [95], aunque este dato no pudo reproducirse en un segundo grupo [96]. El metabolito de la vitamina A, ácido 9-cis-retinoico, redujo la producción inducida por el paludismo de citocinas inflamatorias, particularmente el factor de necrosis tumoral, e incrementó la depuración de eritrocitos infectados por $P$. falciparum a través de la regulación por incremento de la expresión de CD36 en monocitos y macrófagos humanos [97]. Uno u otro mecanismo podría explicar cómo el aporte complementario de vitamina A atenuaría la morbilidad relacionada con el paludismo.

Datos de estudios observacionales han demostrado una asociación negativa entre los niveles séricos de retinol y la magnitud de la parasitemia palúdica en niños [98-101]. En uno de los estudios, las concentraciones séricas basales bajas de retinol se asociaron a un mayor riesgo de parasitemia, mientras que los niveles de retinol se correlacionaban directamente con los títulos de anticuerpos para esporozoitos de $P$. falciparum en 
niños menores de 5 años [98]. La magnitud de la depresión del nivel sérico de retinol era inversamente proporcional a la gravedad de la enfermedad y a la densidad de la parasitemia [102, 103]. Dado que el tratamiento del paludismo causa la elevación de los niveles plasmáticos de retinol y carotenoides [99, 104], se cree que la reducción de los niveles de retinol se debe, por lo menos parcialmente, a la respuesta de fase aguda a la infección $[102,105]$. No obstante, varios factores dificultan el estudio de la asociación entre los niveles de retinol y los desenlaces de la enfermedad. Los procesos inflamatorios inducidos por infecciones febriles llevan al aumento de la excreción de retinol a través de la orina, que puede vaciar rápidamente los depósitos de retinol [93]. Esto puede perpetuar la carencia de vitamina A en niños incluso si se les administran aportes complementarios, lo cual dificulta inferir la causa y el efecto cuando se realiza un estudio de aportes complementarios. Aunque el nivel sérico de retinol se utiliza corrientemente como marcador sucedáneo de la deficiencia, su uso como indicador del estado de vitamina A en regiones endémicas de paludismo es problemático debido a que las concentraciones séricas de retinol declinan durante la respuesta de fase aguda [99], haciendo que sea una medida relativamente insensible de los depósitos hepáticos de vitamina A [106]. Sin embargo, las declinaciones súbitas de los depósitos de retinol en niños con estado de vitamina A marginal pueden resultar en deficiencias clínicas reales.

Prevención del paludismo con el aporte complementario de vitamina A

En varios estudios se ha examinado si la vitamina A podría ser beneficiosa en la prevención del paludismo (tabla 2). En Ghana se realizaron dos ensayos aleatorizados, controlados con placebo (ambos comunicados en una sola publicación) [102]. Mientras que en ambos ensayos se observaba una reducción del $23 \%$ y el $32 \%$ del porcentaje de niños con probable enfermedad palúdica (temperatura $\geq 37,5^{\circ} \mathrm{C}$ y $\geq 4.000$ parásitos/ $\mu$ l) [102], la vitamina A no ejercía ningún impacto evidente sobre las tasas de parasitemia palúdica o las densidades de los parásitos. No obstante, el número de niños con paludismo probable era tan reducido que este estudio carecía de la potencia adecuada para demostrar algún efecto de la vitamina A sobre la morbilidad palúdica confirmada por microscopía. Además, en estos dos ensayos se hizo sólo uso limitado de la vigilancia longitudinal confirmada por microscopía y, en su lugar, se confiaba en la fiebre comunicada como indicador de paludismo [107], lo cual se considera poco fiable como marcador sucedáneo del paludismo [108]. Sin embargo, a pesar de las limitaciones significativas del estudio (es decir, tamaño reducido de la muestra para el paludismo confirmado por microscopía, y marcadores insensibles de la enfermedad), este trabajo daba a entender que la vitamina A puede reducir las tasas de enfermedad clínica y parasitemia. En un estudio subsiguiente controlado con placebo del aporte complementario de vitamina $\mathrm{A}$ en 480 niños de Papúa-Nueva Guinea, se obtuvieron pruebas más sólidas de un beneficio de la vitamina A en la prevención del paludismo. El aporte complementario de vitamina A produjo una reducción del $30 \%$ de los episodios sintomáticos de fiebre terciana maligna $(\mathrm{p}=0,0013)$, con una tendencia hacia una menor densidad media de los parásitos $(\mathrm{p}=0,093)$ y menores tasas de esplenomegalia $(p=0,075)$ [109]. Este beneficio fue más evidente en niños de 12 a 36 meses de edad. Los niños entre 12 y 36 meses de edad también presentaban un número de episodios un 35\% menor de fiebre terciana maligna confirmada por microscopía y una densidad parasitaria un $68 \%$ menor que los del grupo placebo.

En Tanzania, se administraron a niños en edad preescolar aportes suplementarios de vitamina A cada 4 meses, obteniéndose una disminución del riesgo de mortalidad por paludismo [110]. En un estudio en niños hospitalizados de Mozambique, en el que se administró una dosis única de vitamina A a pacientes con paludismo grave, se observó un efecto beneficioso no significativo sobre las tasas de mortalidad nosocomial [111]. No obstante, los efectos no eran significativos sobre la duración de la hospitalización, el tiempo hasta la resolución de la fiebre, la depuración de la parasitemia o el desarrollo de secuelas neurológicas.

En resumen, se dispone de datos a favor de que la carencia de vitamina A puede exacerbar el paludismo y también de que el paludismo de por sí contribuye potencialmente a pérdidas de vitamina A y, en consecuencia, a su deficiencia. El aporte complementario de vitamina A parece proporcionar beneficios uniformes, aunque escasos, a niños en regiones endémicas por reducción de su riesgo de contraer el paludismo.

\section{Hierro}

En regiones del mundo afectadas de paludismo, coexisten el paludismo y la carencia de hierro, siendo su interacción de gran interés para la salud pública. Un episodio agudo de paludismo causa anemia, principalmente a través de la disminución de la producción de los eritrocitos por la médula ósea debido a la supresión de aquéllos y el incremento de la hemólisis [112]. El paludismo contribuye también a la pérdida de hierro por medio de su inmovilización en forma de hemozoína, el aumento de la excreción urinaria [113] y la disminución de la ingestión y la absorción de hierro alimentario [114]. Mientras que hay pocas dudas con respecto al efecto del paludismo sobre la anemia y el estado de hierro en los niños, subsiste todavía la polémica relacionada con el impacto de la deficiencia de hierro y/o el aporte suplementario de hierro sobre la incidencia de paludismo o la progresión desde una parasitemia asintomática hasta un paludismo clínicamente manifiesto. Esta controversia es de gran interés para los profesionales de salud pública porque, a pesar de que en varios estudios se demuestra la eficacia de los aportes complementarios de hierro en la prevención de la anemia, persiste todavía la controversia sobre el empleo de aportes complementarios de hierro en zonas endémi- 
cas de paludismo, debido a los temores de que esta medida pudiera aumentar la vulnerabilidad de los individuos a la infección de paludismo.

\section{Estudios preliminares que dan a entender que el aporte} complementario de hierro exacerba el paludismo

En el humano, ya en la década de los 70 se expuso el papel polémico del hierro en la resistencia o la vulnerabilidad de los hospedadores a la infección de paludismo. Masawe y cols. [115] notificaron casos más frecuentes de paludismo en pacientes ingresados con deficiencia de hierro. En 1978, Murray y cols. [40] hallaron más episodios de paludismo en nómadas somalíes con deficiencia de hierro en campamentos de alimentación tras la suplementación con hierro. En este estudio controlado con placebo, los miembros del grupo suplementado con hierro $(\mathrm{n}=67)$ recibieron $900 \mathrm{mg}$ de sulfato ferroso durante 30 días, mientras que el grupo placebo $(\mathrm{n}=71)$ fue tratado con $3 \mathrm{com}$ primidos de hidróxido de aluminio al día durante el mismo periodo. La observación activa de los episodios febriles, los signos de infecciones y la duración de las mismas y los parásitos en la sangre revelaron 13 casos de paludismo en el grupo de hierro en comparación con sólo 1 en el grupo de control, a pesar de que no se había detectado paludismo en ninguno de los grupos al comienzo del estudio. Los autores supusieron que estos ataques se debían a reactivaciones de infecciones como consecuencia del tratamiento con hierro; no obstante, el estudio fue criticado debido a su corta duración, circunstancia que podría no haber permitido un tiempo suficiente para que el aporte complementario de hierro produjera mejorías de la función inmunitaria para contribuir a rechazar al parásito del paludismo. En el estudio, el tamaño de la muestra era también relativamente reducido y los resultados no pudieron generalizarse debido a que implicaban una población desplazada cuyo estado de salud y otras carencias nutricionales, incluyendo la de hierro, son muy diferentes a los de la población general.

En 1986, Oppenheimer y cols. [116] observaron que lactantes de Papúa-Nueva Guinea con niveles bajos de hemoglobina en el momento del nacimiento tenían menos probabilidad de presentar paludismo durante los primeros años de vida. Los sujetos de control en este estudio fueron emparejados con los sujetos en tratamiento por edad, sexo y vivienda, y recibieron $3 \mathrm{ml}$ de solución salina fisiológica a modo de placebo. El uso de hierro-dextrano parenteral ( $3 \mathrm{ml}$ por lactante con $50 \mathrm{mg} / \mathrm{ml}$ de hierro elemental-Imferon) a los 2 meses de edad se asoció a una mayor prevalencia de paludismo en el seguimiento a los 6 meses y los 12 meses; la diferencia de parasitemia palúdica fue casi dos veces superior en el grupo hierro en comparación con el grupo placebo.

\section{Estudios que sugieren inocuidad del aporte complementario de hierro}

Los resultados de los estudios descritos hasta la fecha permiten suponer un efecto potencialmente protector de la carencia de hierro frente a la infección palúdica y una exacerbación del paludismo durante la repleción de hierro. No obstante, en varios estudios recientes no se ha observado ningún impacto nocivo del aporte complementario de hierro. En un estudio realizado en Gambia, niños escolares (de edades entre 5 y 14 años) sin acceso a fármacos antipalúdicos recibieron un aporte complementario de multimicronutrientes por vía oral incluyendo una dosis elevada de hierro [117]. A los niños del grupo de tratamiento $(\mathrm{n}=200)$ se les administró un aporte complementario de multimicronutrientes 2 veces por semana o un placebo durante 3 meses. El suplemento de micronutrientes se componía de $200 \mathrm{mg}$ de sulfato ferroso, $15 \mathrm{mg}$ de tiamina, 15 $\mathrm{mg}$ de riboflavina y $500 \mathrm{mg}$ de vitamina C. No se observaron diferencias significativas en la incidencia de paludismo entre los grupos, si bien hubo una tendencia a favor de mayores recuentos de parásitos en los niños que recibían el suplemento activo, aunque esto no tuvo significación estadística. En un estudio de 16 semanas en Papúa-Nueva Guinea no se observaron efectos adversos de la suplementación de hierro por vía oral [118]. En este estudio, niños prepuberales $(n=318)$ de 4 escuelas comunitarias, con niveles de hemoglobina de 8 a 12 $\mathrm{g} / \mathrm{dl}$, fueron asignados aleatoriamente para recibir $200 \mathrm{mg}$ de sulfato ferroso o placebo 2 veces al día en la escuela. Los grupos de tratamiento y de control fueron emparejados por edad, hemoglobina y la proporción de eritrocitos de forma oval. Al final del seguimiento no se observaron efectos de la suplementación de hierro sobre la parasitemia, la densidad de los parásitos, los niveles de IgG antipalúdica, el tamaño del bazo o los episodios de paludismo notificados. Los autores supusieron que la inmunidad adquirida podría haber enmascarado el efecto del hierro sobre el paludismo, pero que la ausencia de efectos podría atribuirse también a ciertos defectos del diseño del estudio. Por ejemplo, los episodios de enfermedad se evaluaron preguntando a los niños que se habían ausentado de la escuela durante varios días, si habían estado enfermos o no. Esto podría haber inducido un sesgo de recuerdo y una clasificación errónea no aleatoria, que podría haber atenuado los efectos observados. Por otra parte, la parasitemia palúdica no se evaluó constante o activamente. En su lugar, se realizó a través de encuestas transversales o cuando los niños reportaban enfermedad en la escuela. Este enfoque podría haber resultado en la omisión de algunas infecciones asintomáticas en el transcurso del tiempo.

Menéndez y cols. [119] siguieron a 832 lactantes identificados en el momento del nacimiento y les administraron suplementos de hierro entre las 8 y 24 semanas de vida. En este ensayo factorial, los niños fueron asignados a recibir 1 de 4 tratamientos: (a) hierro diario $(2 \mathrm{mg} / \mathrm{kg})$ más Deltaprim semanal ( $\mathrm{n}=213)$; (b) hierro más placebo semanal ( $\mathrm{n}=204)$; (c) placebo diario más Deltaprim semanal $(\mathrm{n}=208)$; (d) placebo diario más placebo semanal $(\mathrm{n}=207)$. No se observaron efectos del aporte complementario de hierro sobre la frecuencia del paludismo $(0,87$ frente a 1,00 casos por persona-año; efecto protector del $12,8 \%$ en el grupo suplementado con hierro). Los autores llegaron a la conclusión de que el suplemento de 
hierro, administrado a dosis suficientes y durante un periodo adecuado para rellenar los depósitos de hierro, no incrementa la vulnerabilidad al paludismo de los lactantes. En otros dos estudios publicados recientemente, en los que se utilizó una dosis diaria baja de hierro, no se observó ningún impacto negativo de la suplementación de hierro sobre el paludismo [120, 121]. En uno de estos estudios, realizado en Togo, se administró hierro oral diario $(2 \mathrm{mg} / \mathrm{kg})$ durante 3 meses a niños entre 6 y 36 meses de edad, que fueron seguidos de cerca durante el aporte complementario y los 6 meses subsiguientes [120]. Mebrahtu y cols. realizaron un ensayo factorial en Zanzíbar, en el que incluyeron a 614 niños de edades comprendidas entre 4 y 71 meses, a quienes se les asignó aleatoriamente una dosis oral diaria de $10 \mathrm{mg}$ de hierro $(\mathrm{n}=307)$ o placebo $(\mathrm{n}=307)$ y $500 \mathrm{mg}$ de mebendazol o placebo cada 3 meses durante $12 \mathrm{me}$ ses [121]. Los autores de ambos estudios llegaron a la conclusión de la ausencia de diferencias significativas en las morbilidades entre los grupos de tratamiento y control y que la dosis oral diaria baja de hierro no se asociaba a un riesgo de aumento de la prevalencia de la parasitemia o episodios palúdicos clínicos. No obstante, ambos estudios no tenían la potencia suficiente para evaluar la seguridad del aporte complementario con respecto a los ingresos en hospitales o la mortalidad. Por ejemplo, en el estudio de Togo realizado por Berger y cols. [120], el tamaño de la muestra era relativamente reducido ( $n=100$ en el grupo hierro y $n=97$ en el grupo placebo) y disminuyó diferencialmente en un $17 \%$ durante el ensayo, dificultando la extracción de conclusiones confiables de este estudio. En el estudio de Mebrahtu y cols. [121], la parasitemia palúdica se evaluó a intervalos mensuales con diferentes submuestras de niños en meses alternativos. Esto podría haber llevado a omitir algunas infecciones y, por lo tanto, a sesgar los resultados.

Una revisión de 13 ensayos de suplementación, aleatorizados y controlados con placebo (9 publicados y 4 sin publicar) sugiere la probabilidad de que los beneficios conocidos del aporte complementario de hierro superen el riesgo de efectos adversos en regiones con paludismo endémico [122]. Esto presupone que la suplementación de hierro debe continuar incluso en zonas donde el paludismo es prevalente.

\section{Suplementación combinada de hierro y cinc en regiones endémicas de paludismo}

En regiones endémicas de paludismo se efectuaron dos estudios del suplemento combinado de hierro y cinc $[123,124]$. En un estudio en niños de edades comprendidas entre 6 meses y 15 años en la región amazónica peruana se halló que el suplemento de hierro incrementaba la mortalidad debida a $P . v i$ vax; los episodios de fiebre terciana maligna fueron demasiado escasos para evaluar el impacto del hierro sobre $P$. falciparum [124]. En niños menores de 5 años, el cinc, bien sea solo o en combinación con hierro, produjo efectos protectores frente a $P$. vivax. Estos efectos protectores no se hallaron en niños mayores.
No obstante, en un estudio reciente de Sazawal y cols. [123], en el que se evaluó el efecto del suplemento de hierro y ácido fólico sobre la morbilidad y la mortalidad graves por paludismo en Tanzania, se plantearon temores adicionales sobre la seguridad del suplemento de hierro en niños de regiones endémicas de paludismo. Se incluyó a niños menores de 3 años en un ensayo aleatorizado por grupos, con doble enmascaramiento y controlado con placebo. Los niños incluidos fueron asignados aleatoriamente a hierro más ácido fólico, hierro más ácido fólico más cinc, cinc o placebo, y fueron seguidos durante un periodo de un año aproximadamente. En el estudio de Tanzania se administraron $12,5 \mathrm{mg}$ de hierro y $50 \mu \mathrm{g}$ de ácido fólico; los niños de edades comprendidas entre 1 y 11 meses recibieron sólo la mitad de la dosis. Los niños tratados con hierro y ácido fólico, con o sin cinc, presentaron una probabilidad de un 12\% superior (IC 95\%: 2 a 23; p = 0,02) de morir o necesitar tratamiento hospitalario por un efecto adverso y una probabilidad de un $11 \%$ superior ( 1 a $23 \%$; $p=0,03$ ) de ser ingresados en el hospital; en estos grupos se contabilizó también un $15 \%$ más de fallecimientos ( $\mathrm{p}=0,19)$. Los análisis de las causas específicas de los ingresos al hospital y de los fallecimientos confirmaron que el paludismo y otras enfermedades infecciosas aumentaban significativamente en los niños tratados con hierro y ácido fólico. Los resultados de un subestudio dentro de este ensayo también dieron a entender que sólo los niños con deficiencia de hierro por la evaluación de protoporfirina de cinc o que presentaban anemia moderada en situación basal tuvieron tasas significativamente menores de efectos adversos. Este estudio extenso y bien diseñado conlleva varias implicaciones importantes. En primer lugar, añade datos adicionales a la literatura que deja entrever que el suplemento de hierro puede ser nocivo para niños en regiones endémicas de paludismo. En contraste con el posible papel nocivo del hierro, una interacción negativa entre el suplemento de ácido fólico y la SP para el tratamiento del paludismo es una explicación potencial alternativa del aumento de las tasas de efectos adversos observado en el grupo hierro + ácido fólico (se ruega ver más adelante una ampliación de la información acerca del efecto del folato sobre la eficacia de fármacos antipalúdicos cuyo mecanismo implica una actividad antifolato). En segundo lugar, en lugar del suplemento universal de hierro, podría ser más seguro identificar y tratar la anemia causada por carencia de hierro con hierro y ácido fólico en regiones endémicas de paludismo. No obstante, esto conlleva problemas programáticos, dado que no sería fácil detectar deficiencias de hierro antes de poner en práctica un programa de suplementaciones, debido al coste, probablemente elevado, implicado. Por lo tanto, sobre una base demográfica es imprescindible realizar más investigación para identificar la estrategia definitiva en relación con el suplemento de hierro en regiones endémicas de paludismo. 


\section{Folato}

Durante la infección palúdica, el parásito del paludismo induce una declinación del estado de folato del hospedador a través de un incremento de la degradación de los eritrocitos $[125,126]$ y un aumento de la utilización de folato [127]. En varios estudios in vitro e in vivo se ha demostrado también que el folato es crucial para la reproducción, el crecimiento y la supervivencia del parásito del paludismo [128] y que esta necesidad de folato se satisface a través de la síntesis de novo a partir del folato exógeno agregado al medio de crecimiento $[129,130]$. Estas observaciones dejan entrever que la carencia de folato del hospedador puede protegerlo frente al paludismo. De hecho, la supervivencia del parásito del paludismo resultó entorpecida en monos rhesus con deficiencia de folato [131].

En el humano, el efecto del estado de folato sobre la multiplicación del parásito todavía no está definido con claridad. Fleming y Werblinska [125] comunicaron tasas elevadas de paludismo en individuos afectados de anemia megaloblástica. Hamilton y cols. [132] notificaron tasas de infección bajas en mujeres gestantes que consumían una alimentación rica en folato. No obstante, la principal preocupación para la salud pública es si el aporte complementario de folato intensifica o no la proliferación del parásito palúdico y empeora los desenlaces del paludismo a través de su interacción con fármacos antipalúdicos. Esto es importante, dado que la interferencia con el metabolismo del parásito del paludismo mediante la privación de folato al parásito es el mecanismo de acción de varios fármacos, incluyendo la SP y la pirimetamina-dapsona [133]. Estos fármacos actúan inhibiendo la actividad de enzimas del metabolismo del folato (dihidrofolatorreductasa y dihidropteroatosintetasa) con el objetivo de bloquear la síntesis del ADN y detener el crecimiento del parásito.

\section{Impacto de la suplementación con ácido fólico sobre el} tratamiento del paludismo

En un reducido número de estudios se ha indagado la interacción entre la suplementación con ácido fólico y la SP cuando se utilizan conjuntamente en el tratamiento de niños con paludismo agudo. En un estudio realizado en Gambia, el tratamiento concomitante con SP y ácido fólico (5 mg/día) causó una mayor tasa de fallos terapéuticos cerca del día 14 en niños pequeños [134]. En otro estudio realizado en niños en edad preescolar de Gambia no se registraron efectos adversos con respecto al paludismo cuando se administraba un aporte complementario profiláctico de folato junto al tratamiento antipalúdico [135]. En Kenia, pacientes con paludismo clínico (edad media: 80 meses), que recibían 2,5 a $5 \mathrm{mg}$ de ácido fólico al mismo tiempo que un tratamiento con SP, depuraron los parásitos más lentamente que los pacientes del grupo de control durante la primera semana después del tratamiento; sin embargo, la tasa de depuración de parásitos llegó a ser similar en ambos grupos después de algún tiempo y el tratamiento con ácido fólico no afectó la tasa de curaciones clínicas del paludis- mo [136]. Se obtuvieron resultados similares en un estudio realizado en Zambia, en el cual niños con paludismo agudo fueron tratados con SP y una dosis diaria de ácido fólico [137]. La prevalencia de la parasitemia fue significativamente mayor en los que recibieron un aporte complementario diario de $1 \mathrm{mg}$ de ácido fólico al día que en aquellos que recibieron placebo el día 3 después del comienzo del tratamiento, pero no los días 14 ó 28.

En conjunto, estos datos permiten suponer la improbabilidad de que el uso sistemático de suplementos de folato en regiones palúdicas exacerbe el paludismo. No obstante, la utilización de cantidades elevadas de ácido fólico en combinación con fármacos antipalúdicos, cuyo mecanismo de acción consiste en interferir con el metabolismo del folato en el parásito del paludismo, puede menoscabar ligeramente la acción de estos fármacos.

\section{Tiamina}

El paludismo incrementa el metabolismo de la glucosa, precipitando de este modo la carencia de tiamina a través de su mayor utilización [138]. La deficiencia prolongada de tiamina causa el beriberi, un proceso clínico caracterizado por el aumento de la acumulación de ácido láctico o la acidosis láctica. Dicha acidosis es una complicación significativa del paludismo grave [139]. En algunos estudios se ha demostrado que la carencia de tiamina es un factor de riesgo del paludismo complicado o no complicado. Krishna y cols. [140] demostraron que la deficiencia de tiamina complica corrientemente la fiebre terciana maligna aguda en adultos de Tailandia. En este estudio, los adultos afectados de paludismo presentaban una mayor deficiencia de tiamina que los controles, y los individuos con paludismo grave tenían una mayor deficiencia de tiamina que los afectados de paludismo no complicado. En un estudio más reciente realizado en Laos [141], el 30\% de los pacientes (mayores de 1 año) que acudían por paludismo causado por $P$. falciparum no complicado presentaban signos bioquímicos de carencia de tiamina (actividad de transcetolasa eritrocítica $\geq 1,25$ ) y el $12 \%$ sufrían de deficiencia bioquímica grave. Estos resultados dan a entender que la deficiencia de tiamina es un factor de riesgo del paludismo no complicado y del paludismo grave. Sin embargo, es imprescindible la realización de más investigación para confirmar estos resultados y evaluar el uso de la tiamina como tratamiento coadyuvante del tratamiento antipalúdico.

\section{Vitamina E}

La vitamina $\mathrm{E}$ ha sido involucrada en el curso clínico del paludismo, tanto en animales como en humanos. En varios estudios de experimentación animal se ha descrito una protección frente al paludismo cuando se alimenta a ratones con una 
dieta carente de vitamina E [142-146]. El primer estudio en este ámbito fue realizado por Godfrey [146] en 1957; este autor observó que una dieta carente de vitamina E que contenía aceite de hígado de bacalao inhibía el crecimiento de P. berghei y que esta potente acción antiparasitaria era invertida cuando se añadía vitamina E a la dieta. Levander y cols. [142-144] realizaron observaciones similares en tres estudios por separado, en los cuales una dieta carente de vitamina E que contenía aceite de pescado disminuía la parasitemia palúdica en ratones. En uno de estos estudios, una dieta carente de vitamina $\mathrm{E}$ con un $5 \%$ de aceite de hígado de bacalao presentaba una potente actividad antipalúdica frente a $P$. yoelii, en tal medida que no podía demostrarse el beneficio adicional de un fármaco antipalúdico (qinghaosu) cuando este fármaco y la dieta se administraban concomitantemente [142]. En otro ensayo, una dieta carente de vitamina E que contenía un 5\% de aceite de una especie de sábalo confería protección frente a parásitos Plasmodium tanto sensibles a la CQ como resistentes a la CQ [143].

Los resultados de un número limitado de estudios en humanos reflejan la relación inversa entre el estado de vitamina E y el paludismo. El recrudecimiento del paludismo en el momento de alimentar a nómadas somalíes afectados de hambruna, observado por Murray y cols. [35], se atribuyó al consumo de granos de cereales con elevado contenido en vitamina $\mathrm{E}$, si bien esta hipótesis no fue confirmada en estudios experimentales. No obstante, esta hipótesis se basaba en que la aparición de paludismo grave se limitaba a los niños nómadas que ingerían cereales, mientras que los niños que subsistían exclusivamente con leche no presentaban este tipo de complicación [147]. En algunos estudios se monitorizaron los niveles plasmáticos de vitamina $\mathrm{E}$ en pacientes con paludismo que acudían a un hospital. En estos estudios se demostró que los pacientes palúdicos que se presentan con concentraciones séricas bajas de vitamina $\mathrm{E}$ se recuperan más rápidamente de los episodios de paludismo clínico que sus controles respectivos [148, 149].

Se considera que la propiedad antioxidante de la vitamina E es el mecanismo principal que subyace a los efectos antipalúdicos de la carencia de dicha vitamina. Se ha observado que especies de oxígeno muy reactivas, producidas por la respuesta inmunitaria a la infección de paludismo, destruyen los parásitos palúdicos intraeritrocíticos, tanto en estudios in vitro como en estudios in vivo $[150,151]$. Por otra parte, la vitamina E protege los tejidos corporales del daño oxidativo eliminando los radicales libres de oxígeno que emergen de reacciones metabólicas en el organismo. Esto da a entender que una deficiencia de antioxidantes como la vitamina E podría ser protectora frente al paludismo por aumento de la vulnerabilidad del parásito al ataque de los radicales libres.

Sin embargo, en algunos estudios en humanos se ha demostrado que el nivel sérico total de $\alpha$-tocoferol disminuye en los pacientes palúdicos en relación con los controles sanos [152]. No obstante, la disminución del nivel sérico de $\alpha$-tocoferol no significa que el sujeto presente necesariamente una carencia de
Tabla 3. Impacto potencial de las deficiencias de micronutrientes sobre el paludismo

\begin{tabular}{|c|c|c|}
\hline $\begin{array}{l}\text { Micro- } \\
\text { nutriente }\end{array}$ & Efecto & Supuesto mecanismo \\
\hline Vitamina A & Adverso & $\begin{array}{l}\text { Deterioro de la función inmunitaria, } \\
\text { incremento de la vulnerabilidad a la } \\
\text { parasitemia, aumento de los episo- } \\
\text { dios de paludismo y aumento de la } \\
\text { mortalidad }\end{array}$ \\
\hline Cinc & Adverso & $\begin{array}{l}\text { Deterioro de la función inmunitaria, } \\
\text { incremento de la vulnerabilidad a la } \\
\text { parasitemia, aumento de los episo- } \\
\text { dios de paludismo y aumento de la } \\
\text { mortalidad }\end{array}$ \\
\hline Hierro & Protector & $\begin{array}{l}\text { Disminución de la vulnerabilidad a } \\
\text { la parasitemia, deterioro de la eritro- } \\
\text { poyesis, reducción de los episodios } \\
\text { de paludismo, disminución de la } \\
\text { mortalidad }\end{array}$ \\
\hline Folato & Adverso & $\begin{array}{l}\text { Aumento de la vulnerabilidad a la } \\
\text { parasitemia, incremento de los episo- } \\
\text { dios de paludismo, aumento de la } \\
\text { mortalidad }\end{array}$ \\
\hline
\end{tabular}

Vitamina E Protector Disminución de la actividad antioxidante, incremento de la depuración de los parásitos por los radicales de oxígeno

\begin{tabular}{lll}
\hline Tiamina & Adverso & $\begin{array}{l}\text { Incremento de la acidosis plasmática, } \\
\text { aumento de la complicación del } \\
\text { paludismo }\end{array}$ \\
\hline Riboflavina & Dudoso & $\begin{array}{l}\text { Disminución de la parasitemia, pero } \\
\text { incremento de la morbilidad en algu- } \\
\text { nos estudios }\end{array}$ \\
\hline
\end{tabular}

Selenio Desconocido

vitamina $\mathrm{E}$, dado que esta disminución podría deberse a la respuesta de fase aguda a la infección de paludismo. Davis y cols. [148] observaron una asociación inversa entre el nivel plasmático de $\alpha$-tocoferol y los índices bioquímicos de la función hepática en pacientes con paludismo grave, prueba indicativa del menoscabo de la liberación de vitamina $\mathrm{E}$ a partir del hígado durante la infección de paludismo.

En resumen, se dispone de datos sustanciales de modelos de experimentación animal en sentido de que la carencia de vitamina E contribuye a producir un efecto protector frente al paludismo. Mientras que los datos de los estudios en humanos son limitados y se complican por las dificultades de interpretación del estado de la vitamina $\mathrm{E}$ en el ámbito de la respuesta de fase aguda asociada al paludismo, existe, sin embargo, el temor de que el aporte complementario de vitamina E pudiera 
exacerbar las infecciones de paludismo en el humano, aunque es imprescindible la realización de más estudios en humanos para respaldar esta afirmación.

\section{Conclusiones}

El paludismo es una causa muy importante de morbilidad y mortalidad infantil, especialmente en los niños que habitan en el África subsaharina. Mientras que los episodios de paludismo producen claramente efectos negativos sobre la ganancia de peso y el crecimiento lineal de los niños, el impacto de la desnutrición subyacente sobre el riesgo de adquisición de paludismo y la gravedad de la infección es complejo.

En el curso de la última década se ha producido un desplazamiento importante hacia el uso de la TCA para el tratamiento del paludismo pediátrico, tanto de la forma no complicada como de la forma grave de la enfermedad. Este movimiento a favor de los tratamientos más eficaces y bien tolerados del paludismo se ha visto complicado por problemas en el tratamiento de casos en el nivel de atención primaria en áreas rurales de África y Asia. Mientras que las opciones terapéuticas han mejorado, también se ha incrementado la energía dirigida al perfeccionamiento de los métodos preventivos. Parece que pueda desempeñar algún papel el uso de determinados micronutrientes, especialmente vitamina A y cinc, para la prevención del paludismo en niños pequeños (tabla 2). No obstante, otras vitaminas esenciales, como la vitamina $\mathrm{E}$ y el ácido fólico, pueden desempeñar papeles potencialmente nocivos por la exacerbación de los episodios de paludismo o interferencia con el tratamiento antipalúdico. En consecuencia, aunque el uso de múltiples micronutrientes parecería ser un abordaje ideal para intensificar el estado nutricional de niños pequeños en regiones endémicas de paludismo, es imprescindible la realización de más investigación para determinar la seguridad y la eficacia de este abordaje.

\section{Bibliografía}

1 Guerin PJ, Olliaro P, Nosten F, et al: Malaria: current status of control, diagnosis, treatment, and a proposed agenda for research and development. Lancet Infect Dis 2002;2: 564-573.

2 Rowe AK, Rowe SY, Snow RW, et al: The burden of malaria mortality among African children in the year 2000. Int J Epidemiol 2006;35:691-704.

-3 Snow RW, Craig M, Deichmann U, Marsh K: Estimating mortality, morbidity and disability due to malaria among Africa's non-pregnant population. Bull World Health Organ 1999;77:624-640.

4 Snow RW, Trape JF, Marsh K: The past, present and future of childhood malaria mortality in Africa. Trends Parasitol 2001;17:593597.

5 Trape JF, Pison G, Preziosi MP, et al: Impact of chloroquine resistance on malaria mortality. CR Acad Sci III 1998;321:689-697.

6 Zucker JR, Ruebush TK, Obonyo C, et al: The mortality consequences of the continued use of chloroquine in Africa: experience in Siaya, western Kenya. Am J Trop Med Hyg 2003; 68:386-390.

7 Korenromp E, Williams B, Gouws E, et al: Measuring trends in childhood malaria mortality in Africa: a new assessment of progress toward targets based on verbal autopsy. Lancet Infect Dis 2003;3:349-358.

8 Greenwood B, Mutabingwa T: Malaria in 2002. Nature 2002;415:670-672.

9 Snow RW, Guerra CA, Noor AM, et al: The global distribution of clinical episodes of Plasmodium falciparum malaria. Nature 2005;434:214-217.

10 Breman JG: The ears of the hippopotamus: manifestations, determinants, and estimates of the malaria burden. Am J Trop Med Hyg 2001;64:1-11.

11 Greenwood BM, Bradley AK, Greenwood $\mathrm{AM}$, et al: Mortality and morbidity from malaria among children in a rural area of The Gambia, West Africa. Trans R Soc Trop Med Hyg 1987;81:478-486.

12 Trape JF, Zoulani A, Quinn TC: Assessment of the incidence and prevalence of clinical malaria in children exposed to intense and perennial transmission. Am J Epidemiol 1987;126:193-201.

13 Steketee RW, Nahlen BL, Parise ME, Menendez C: The burden of malaria in pregnancy in malaria-endemic areas. Am J Trop Med Hyg 2001;64:28-35.

14 Guyatt HL, Snow RW: Malaria in pregnancy as an indirect cause of infant mortality in sub-Saharan Africa. Trans R Soc Trop Med Hyg 2001;95:569-576.

15 Guyatt HL, Snow RW: Impact of malaria during pregnancy on low birth weight in sub-Saharan Africa. Clin Microbiol Rev 2004;17:760-769.

16 Steketee RW, Wirima JJ, Bloland PB, et al: Impairment of a pregnant woman's ability to limit Plasmodium falciparum by infection with human immunodeficiency virus type 1 . Am J Trop Med Hyg 1996;88:150-154.

17 Verhoeff FH, Brabin BJ, van Buuren S, et al: Increased prevalence of malaria in HIV-infected pregnant women and its implications for malaria control. Trop Med Int Health 1999;4:5-12.

18 World Health Organization: World Health Report. Geneva, WHO, 2002.

19 McCarthy D, Wolf H, Wu Y: Malaria and Growth. Working Paper. Washington, World Bank, 1999.
20 Gallup J, Sachs J: The Economic Burden of Malaria. Working Paper 52. Cambridge, Center for International Development, Harvard University, 2000.

21 World Health Organization: Guidelines for the Treatment of Malaria. Geneva, WHO, 2006. WHO/HTM/MAL/2006.1108.

22 World Health Organization: Severe falciparum malaria. Trans R Soc Trop Med Hyg 2000;94(suppl 1):S1-S90.

23 Marsh K, Forster D, Waruiru C, et al: Indicators of life-threatening malaria in African children. N Engl J Med 1995;332:1399-1404.

24 Mockenhaupt FP, Ehrhardt S, Burkhardt J, et al: Manifestation and outcome of severe malaria in children in northern Ghana. Am J Trop Med Hyg 2004;71:167-172.

25 Tripathy R, Parida S, Das L, et al: Clinical manifestations and predictors of severe malaria in Indian children. Pediatrics 2007;12: e454-e460.

26 McGregor IA: Malaria: nutritional implications. Rev Infect Dis 1982;4:798-804.

27 Marsden PD: The Sukuta Project. A longitudinal study of health in Gambian children from birth to 18 months of age. Trans R Soc Trop Med Hyg 1964;58:455-489.

28 Rowland MG, Cole TJ, Whitehead RG: A quantitative study into the role of infection in determining nutritional status in Gambian village children. Br J Nutr 1977;37:441450.

29 McGregor IA, Gilles HM, Walters JH, Davies AH: Effects of heavy and repeated malaria infections on Gambian infants and children. Effects of erythrocyte parasitization. Br Med J 1956;2:686-692.

30 Nyakeriga AM, Troye-Blomberg M, Chemtai AK, et al: Malaria and nutritional status 
in children living on the coast of Kenya. Am J Clin Nutr 2004;80:1604-1610.

- 31 Bradley-Moore AM, Greenwood BM, Bradley $\mathrm{AK}$, et al: Malaria chemoprophylaxis with chloroquine in young Nigerian children. III. Its effect on nutrition. Ann Trop Med Parasitol 1985;79:575-584.

32 ter-Kuile FO, Terlouw DJ, Kariuki S, et al: Impact of permethrin-treated bed nets on malaria, anemia, and growth in infants in an area of intense perennial malaria transmission in western Kenya. Am Soc Trop Med Hyg 2003;68(suppl 4):68-77.

-33 Snow RW, Molyneux CS, Njeru EK, et al: The effects of malaria control on nutritional status in infancy. Acta Trop 1997;65:1-10.

- 34 Archibald HM, Bruce-Chwatt LJ: Suppression of malaria with pyrimethamine in Nigerian school children. Bull World Health Organ 1956;15:775-784.

- 35 Murray MJ, Murray AB, Murray NJ, Murray MB: Diet and cerebral malaria: the effect of famine and refeeding. Am J Clin Nutr 1978; 31:57-61.

-36 Edington G: Cerebral malaria in the Gold Coast African: four autopsy reports. Ann Trop Med Parasitol 1954;48:300-306.

- 37 Hendrickse RG, Hasan AH, Olumide LO, Akinkunmi A: Malaria in early childhood. An investigation of five hundred seriously ill children in whom a 'clinical' diagnosis of malaria was made on admission to the children's emergency room at University College Hospital, Ibadan. Ann Trop Med Parasitol 1971;65:1-20.

-38 Murray MJ, Murray NJ, Murray AB, Murray MB: Refeeding malaria and hyperferraemia. Lancet 1975;1:653-654.

-39 Murray MJ, Murray AB, Murray MB, Murray $\mathrm{CJ}$ : Somali food shelters in the Ogaden famine and their impact on health. Lancet 1976;1:1283-1285.

40 Murray MJ, Murray AB, Murray MB, Murray $C J$ : The adverse effect of iron repletion on the course of certain infections. Br Med J 1978;2:1113-1115.

41 Ahmad SH, Moonis R, Shahab T, et al: Effect of nutritional status on total parasite count in malaria. Indian J Pediatr 1985;52:285288.

\$2 Olumese PE, Sodeinde O, Ademowo OG, Walker O: Protein energy malnutrition and cerebral malaria in Nigerian children. J Trop Pediatr 1997;43:217-219.

43 Genton B, Al Yaman F, Ginny M, et al: Relation of anthropometry to malaria morbidity and immunity in Papua New Guinean children. Am J Clin Nutr 1998;68:734-741.

44 el Samani FZ, Willett WC, Ware JH: Nutritional and socio-demographic risk indicators of malaria in children under five: a cross-sectional study in a Sudanese rural community. J Trop Med Hyg 1987;90:69-78.

45 Mbago MCY, Namfua PP: Some determinants of nutritional status of one to four year old children in low-income urban areas of Tanzania. J Trop Pediatr 1991;38:299-306.
46 Renaudin P, Lombart JP: Anemia in infants less than 1 year old in Moundou, Chad: prevalence and etiology (in French). Med Trop (Mars) 1994;54:337-342.

-47 Tshikuka J, Gray-Donald K, Scott M, Olela $\mathrm{KN}$ : Relationship of childhood protein-energy malnutrition and parasite infections in an urban African setting. Trop Med Int Health 1997;2:374-382.

48 Williams TN, Maitland K, Phelps L, et al: Plasmodium vivax: a cause of malnutrition in young children. QJM 1997;90:751-757.

49 Snow RW, Byass P, Shenton FC, Greenwood BM: The relationship between anthropometric measurements and measurements of iron status and susceptibility to malaria in Gambian children. Trans R Soc Trop Med Hyg 1991;85:584-589.

50 Shankar AH: Nutritional modulation of malaria morbidity and mortality. J Infect Dis 2000;182(suppl 1):S37-S53.

51 Moody A: Rapid diagnostic tests for malaria parasites. Clin Microbiol Rev 2002;15:6678.

52 Bell D, Wongsrichanalai C, Barnwell JW: Ensuring quality and access for malaria diag nosis: how can it be achieved? Nat Rev Microbiol 2006;4(suppl):S7-S20.

53 Gove S: Integrated management of childhood illness by outpatient health workers: technical basis and overview. Bull World Health Organ 1997;75(suppl 1):7-24.

54 Amexo M, Tolhurst R, Barnish G, Bates I: Malaria misdiagnosis: effects on the poor and vulnerable. Lancet 2004;364:18961898 .

55 Reyburn H, Mbatia R, Drakeley C, et al: Overdiagnosis of malaria in patients with severe febrile illness in Tanzania: a prospective study. BMJ 2004;329:1212.

56 Perkins BA, Zucker JR, Otieno J, et al: Evaluation of an algorithm for integrated management of childhood illness in an area of Kenya with high malaria transmission. Bull World Health Organ 1997;75(suppl 1):33-42.

- 57 Kilian AH, Kabagambe G, Byamukama W, et al: Application of the ParaSight-F dipstick test for malaria diagnosis in a district control program. Acta Trop 1999;72:281-293.

-58 Hamer DH, Ndhlovu M, Zurovac D, et al: Does improving coverage of parasitological diagnostic tests change malaria treatment practices? An operational cross-sectional study in Zambia. JAMA 2007;297:22272231.

59 Reyburn H, Mbakilwa H, Mwangi R, et al: Rapid diagnostic tests compared with malaria microscopy for guiding outpatient treatment of febrile illness in Tanzania: randomised trial. BMJ 2007;334:403.

60 White NJ: The treatment of malaria. N Engl J Med 1996:335:800-806.

61 World Health Organization: Roll Back Malaria. Geneva, WHO, 2003.

62 Bloland PB, Kazembe PN, Oloo AJ, et al: Chloroquine in Africa: critical assessment and recommendations for monitoring and evaluating chloroquine therapy efficacy in sub-Saharan Africa. Trop Med Int Health 1998;3:543-552.

63 Hamer DH, MacLeod W, Addo-Yobo E, et al: Age, temperature, and parasite density predict chloroquine treatment failure in children with uncomplicated falciparum malaria. Trans R Soc Trop Med Hyg 2003;97: 422-428.

64 East African Network for Monitoring Antimalarial Treatment (EANMAT): The efficacy of antimalarial monotherapies, sulphdoxine-pyrimethamine and amodiaquine in East Africa: implications for sub-regional policy. Trop Med Int Health 2003;8:860867.

65 Nosten F, Brasseur P: Combination therapy for malaria: the way forward? Drugs 2002;62: 1315-1329.

66 Kremsner PG, Krishna S: Antimalarial combinations. Lancet 2004;364:285-294.

67 World Health Organization, Bosman A, Delacollette C, Olumese PE, Ret al: The Use of Antimalarial Drugs: Report of An Informal Consultation. Geneva, WHO, 2001.

68 Staedke SG, Mpimbaza A, Kamya MR, et al: Combination treatments for uncomplicated falciparum malaria in Kampala, Uganda: randomised clinical trial. Lancet 2004;364: 1950-1957.

69 Omari A, Preston C, Garner P: Artemetherlumefantrine for treating uncomplicated falciparum malaria. Cochrane Database Syst Rev 2002;(3):CD003125.

70 Rowe AK, Hamel MJ, Flanders WD, et al: Predictors of correct treatment of children with fever seen at outpatient health facilities in a rural Tanzanian district. Am J Epidemiol 2000;151:1029-1035.

71 Eriksen J, Tomson G, Mujinja PGM, et al: Assessing health worker performance in malaria case management of underfives at health facilities in a rural Tanzanian district. Trop Med Int Health 2007;12:52-61.

72 Zurovac D, Ndhlovu M, Rowe AR, et al: Treatment of paediatric malaria during a period of drug transition to artemether-lumefantrine in Zambia: cross-sectional study. BMJ 2005;331:734-737.

73 Zurovac D, Ndhlovu M, Sipilanyambe N, et al: Pediatric malaria case management with artemether-lumefantrine in Zambia: a longitudinal study of changing practice. Malar J 2007;6:31.

74 Zurovac D, Njogu J, Akhwale WS, et al: Translation of artemether-lumefantrine treatment policy into paediatric clinical practice: an early experience from Kenya. Trop Med Int Health 2008, in press.

75 Murphy GS, Basri H, Purnomo, et al: Vivax malaria resistant to treatment and prophylaxis with chloroquine. Lancet 1993;341:96100

76 Falade C, Makanga M, Premji Z, et al: Efficacy and safety of artemether-lumefantrine (Coartem) tablets (six-dose regimen) in African infants and children with acute, un- 
complicated falciparum malaria. Trans $\mathrm{R}$ Soc Trop Med Hyg 2005;99:459-467.

-77 Zinc Against Plasmodium (ZAP) Study Group: Effect of zinc on the treatment of Plasmodium falciparum malaria in children: a randomized controlled trial. Am J Clin Nutr 2002;76:805-812.

-78 Duggan C, MacLeod W, Krebs NF, et al: Plasma zinc concentrations are depressed during the acute phase response in children with falciparum malaria. J Nutr 2005;135:802-807.

-79 South East Asian Quinine Artesunate Malaria Trial group: Artesunate versus quinine for treatment of severe falciparum malaria: a randomised trial. Lancet 2005;366:717-725.

-80 Karunajeewa HA, Manning L, Mueller I, et al: Rectal administration of artemisinin derivatives for the treatment of malaria. JAMA 2007;297:2381-2390.

-81 Bronzan RN, Taylor TE, Mwenechanya M, et al: Bacteremia in Malawian children with severe malaria: prevalence, etiology, HIV coinfection, and outcome. J Infect Dis 2007;195: 895-904.

-82 Treluyer JM, Roux A, Mugnier C, et al: Metabolism of quinine in children with global malnutrition. Pediatr Res 1996;40:558563.

83 Salako LA, Sowunmi A, Akinbami FO: Pharmacokinetics of quinine in African children suffering from kwashiorkor. Br J Clin Pharmacol 1989;28:197-201.

-84 Pussard E, Barennes H, Daouda H, et al: Quinine disposition in globally malnourished children with cerebral malaria. Clin Pharmacol Ther 1999;65:500-510.

85 Breman JG: The ears of the hippopotamus: manifestations, determinants, and estimates of the malaria burden. Am J Trop Med Hyg 2001;64:1-11.

86 Prasad AS: Zinc deficiency. BMJ 2003;326: 409-410.

87 Shankar AH, Prasad AS: Zinc and immune function: the biological basis of altered resistance to infection. Am J Clin Nutr 1998; 68(suppl):447S-463S.

88 Bates CJ, Evans PH, Dardenne M, et al: A trial of zinc supplementation in young rural Gambian children. Br J Nutr 1993;69:243255.

89 Shankar AH, Genton B, Baisor M, et al: The influence of zinc supplementation on morbidity due to Plasmodium falciparum: a randomized trial in preschool children in Papua New Guinea. Am J Trop Med Hyg 2000;62: 663-669.

$\$ 90$ Muller O, Becher $\mathrm{H}$, van Zweeden AB, et al: Effect of zinc supplementation on malaria and other causes of morbidity in West African children: randomised double blind placebo controlled trial. BMJ 2001;322:1-5.

-91 Zinc Investigators' Collaborative Group: Prevention of diarrhea and pneumonia by zinc supplementation in children in developing countries: pooled analysis of randomized controlled trials. J Pediatr 1999;135: 689-697.
92 Zeba AN, Sorgho H, Rouamba N, et al: Major reduction of malaria morbidity with combined vitamin A and zinc supplementation in young children in Burkina Faso: a randomized double blind trial. Nutr J 2008;7:7.

$\checkmark 93$ Semba RD: The role of vitamin A and related retinoids in immune function. Nutr Rev 1998;56:S38-S48.

94 Villamor E, Fawzi WW: Vitamin A supplementation: implications for morbidity and mortality in children. J Infect Dis 2000; 182(suppl 1):S122-S133.

95 Davis TM, Skinner-Adams TS, Beilby J: In vitro growth inhibition of Plasmodium falciparum by retinol at concentrations present in normal human serum. Acta Trop 1998;69:111-119.

-96 Samba DC, Basco LK, Bleiberg-Daniel F, et al: Absence of effect of retinol on the in vitro development of Plasmodium falciparum. Int J Vitam Nutr Res 1992;62:99100.

97 Serghides L, Kain KC: Peroxisome proliferator-activated receptor gamma-retinoid $\mathrm{X}$ receptor agonists increase CD36-dependent phagocytosis of Plasmodium falciparum-parasitized erythrocytes and decrease malaria-induced TNF-alpha secretion bymonocytes/macrophages. JImmunol 2001;166:6742-6748.

$\$ 98$ Sturchler D, Tanner M, Hanck A, et al: A longitudinal study on relations of retinol with parasitic infections and the immune response in children of Kikwawila village, Tanzania. Acta Trop 1987;44:213-227.

99 Thurnham DI, Singkamani R: The acute phase response and vitamin A status in malaria. Trans R Soc Trop Med Hyg 1991; 85:194-199.

100 Friis H, Mwaniki D, Omondi B, et al: Serum retinol concentrations and Schistosoma mansoni, intestinal helminths, and malarial parasitemia: a cross-sectional study in Kenyan preschool and primary school children. Am J Clin Nutr 1997;66:665-671.

101 Filteau SM, Morris SS, Abbott RA, et al: Influence of morbidity on serum retinol of children in a community-based study in northern Ghana. Am J Clin Nutr 1993;58: 192-197.

102 Binka FN, Ross DA, Morris SS, et al: Vitamin A supplementation and childhood malaria in northern Ghana. Am J Clin Nutr 1995;61:853-859.

103 Hautvast JL, Tolboom JJ, West CE, et al: Malaria is associated with reduced serum retinol levels in rural Zambian children. Int J Vitam Nutr Res 1998;68:384-388.

104 Metzger A, Mukasa G, Shankar AH, et al: Antioxidant status and acute malaria in children in Kampala, Uganda. Am J Trop Med Hyg 2001;65:115-119.

105 Fawzi WW: Environmental factors that impact the efficacy of vitamin A supplements among children. Environ Nutr Interact 1997;1:299-333.
106 Flores H, Campos F, Araujo RC, Underwood BA: Assessment of marginal vitamin A deficiency in Brazilian children using the relative dose response procedure. Am J Clin Nutr 1984;40:1281-1289.

107 Shankar AH: Vitamin A and malaria. Am J Clin Nutr 1995;62:842-843.

108 Einterz EM, Bates ME: Fever in Africa: do patients know when they are hot? Lancet 1997;350:781-782.

109 Shankar AH, Genton B, Semba RD, et al: Effect of vitamin A supplementation on morbidity due to Plasmodium falciparum in young children in Papua New Guinea: a randomised trial. Lancet 1999;354:203209.

110 Fawzi WW, Mbise RL, Hertzmark E, et al: A randomized trial of vitamin A supplements in relation to mortality among human immunodeficiency virus-infected and uninfected children in Tanzania. Pediatr Infect Dis J 1999;18:127-133.

- 111 Varandas L, Julien MR, Gomes A, et al: A randomized, double-blind, placebo controlled trial of vitamin A in severe malaria in hospitalized Mozambican children. Ann Trop Paediatr 2001;21:211-222.

112 Phillips RE, Looareesuwan S, Warrell DA, et al: The importance of anaemia in cerebral and uncomplicated falciparum malaria: role of complications, dyserythropoiesis and iron sequestration. Q J Med 1986;58: 305-323.

113 Brabin BJ: The role of malaria in nutritional anemias; in Fomon SJ, Slotkin S (eds) Nutritional Anemias. New York, Raven Press, 1992, pp 65-80.

114 Molyneux ME, Looareesuwan S, Menzies IS, et al: Reduced hepatic blood flow and intestinal malabsorption in severe falciparum malaria. Am J Trop Med Hyg 1989; 40:470-476.

115 Masawe AE, Muindi JM, Swai GB: Infections in iron deficiency and other types of anaemia in the tropics. Lancet 1974;2:314317.

116 Oppenheimer SJ, Gibson FD, Macfarlane $\mathrm{SB}$, et al: Iron supplementation increases prevalence and effects of malaria: report on clinical studies in Papua New Guinea. Trans R Soc Trop Med Hyg 1986;80:603-612.

117 Bates CJ, Powers HJ, Lamb WH, et al: Effect of supplementary vitamins and iron on malaria indices in rural Gambian children. Trans R Soc Trop Med Hyg 1987;81:286291.

118 Harvey PW, Heywood PF, Nesheim MC, et al: The effect of iron therapy on malarial infection in Papua New Guinean schoolchildren. Am J Trop Med Hyg 1989;40:1218.

119 Menendez C, Kahigwa E, Hirt R, et al: Randomised placebo-controlled trial of iron supplementation and malaria chemoprophylaxis for prevention of severe anaemia and malaria in Tanzanian infants. Lancet 1997;350:844-850. 
120 Berger J, Dyck JL, Galan P, et al: Effect of daily iron supplementation on iron status, cell-mediated immunity, and incidence of infections in 6-36 month old Togolese children. Eur J Clin Nutr 2000;54:29-35.

121 Mebrahtu T, Stoltzfus RJ, Chwaya HM, et al: Low-dose daily iron supplementation for 12 months does not increase the prevalence of malarial infection or density of parsites in young Zanzibari children. J Nutr 2004;134:3037-3041.

122 International Nutritional Anemia Consultative Group: Safety of iron supplementation programs in malaria-endemic regions. Acta Trop 2002;82:321-327.

123 Sazawal S, Black RE, Ramsan M, et al: Effects of routine prophylactic supplementation with iron and folic acid on admission to hospital and mortality in pre-school children in a high malaria transmission setting: community-based, randomised, placebo-controlled trial. Lancet 2006;367: 133-143.

-124 Richard SA, Zavaleta N, Caulfield LE, et al: Zinc and iron supplementation and malaria, diarrhea, and respiratory infections in children in the Peruvian Amazon. Am J Trop Med Hyg 2006;75:126-132.

125 Fleming AF, Werblinska B: Anaemia in childhood in the Guinea savanna of Nigeria. Ann Trop Paediatr 1982;2:161-173.

126 Fleming AF, Hendrickse JP, Allan NC: The prevention of megaloblastic anaemia in pregnancy in Nigeria. J Obstet Gynaecol Br Commonw 1968;75:425-432.

127 Brabin BJ, van den Berg H, Nijmeyer F: Folacin, cobalamin, and hematological status during pregnancy in rural Kenya: the influence of parity, gestation, and Plasmodium falciparum malaria. Am J Clin Nutr 1986; 43:803-815.

128 Peters W: Chemotherapy and Drug Resistance in Malaria. London, Academic Press, 1997.

129 Krungkrai J, Webster HK, Yothavong Y: De novo and salvage biosynthesis of pteroylpentaglutamates in the human malaria parasite, Plasmodium falciparum. Mol Biochem Parasitol 1989;32:25-37.

130 Stokstad ELR, Koch J: Folic acid metabolism. Physiol Rev 1967;47:83-116.
131 Das KC, Virdi JS, Herbert G: Survival of the dietarily deprived: folate deficiency protects against malaria in primates. Blood 1992;80:281a.

132 Hamilton PJ, Gebbie DA, Wilks NE, Lothe F: The role of malaria, folic acid deficiency and haemoglobin AS in pregnancy at $\mathrm{Mu}$ lago Hospital. Trans R Soc Trop Med Hyg 1972;66:594-602.

133 Gregson A, Plowe CV: Mechanisms of resistance of malaria parasites to antifolates. Pharmacol Rev 2005;57:117-145.

134 van Hensbroek MB, Morris-Jones S, Meisner S, et al: Iron, but not folic acid, combined with effective antimalarial therapy promotes haematological recovery in African children with acute falciparum malaria. Trans R Soc Trop Med Hyg 1995;89:672676.

135 Fuller NJ, Bates CJ, Hayes RJ, et al: The effects of antimalarials and folate supplements on haemtological indices and red cell folate levels in Gambian children. Ann Trop Paediatr 1988;8:61-67.

136 Carter JY, Loolpapit M, Lema OE, et al: Folic acid supplementation reduces the efficacy of antifolate antimalarial activity. Am J Trop Med Hyg 2005;73:166-170.

137 Mulenga M, Malunga F, Bennett S, et al: A randomised, double-blind, placebo-controlled trial of atovaquone-proguanil vs. sulphadoxine-pyrimethamine in the treatment of malarial anaemia in Zambian children. Trop Med Int Health 2006;11:16431652.

138 Mayxay M, Taylor AM, Khanthavong M, et al: Thiamin deficiency and uncomplicated falciparum malaria in Laos. Trop Med Int Health 2007;12:363-369.

139 Mayxay M, Pukritrayakamee S, Chotivanich $\mathrm{K}$, et al: Identification of cryptic coinfection with Plasmodium falciparum in patients presenting with vivax malaria. Am J Trop Med Hyg 2001;65:588-592.

140 Krishna S, Taylor AM, Supanaranond W, et al: Thiamine deficiency and malaria in adults from southeast Asia. Lancet 1999; 353:546-549.

- 141 Mayxay M, Chotivanich K, Pukrittayakamee S, et al: Contribution of humoral immunity to the therapeutic response in falciparum malaria. Am J Trop Med Hyg 2001; 65:918-923.
42 Levander OA, Ager ALJ, Morris VC, May RG: Qinghaosu, dietary vitamin E, selenium, and cod-liver oil: effect on the susceptibility of mice to the malarial parasite Plasmodium yoelii. Am J Clin Nutr 1989;50: 346-352.

143 Levander OA, Ager ALJ, Morris VC, May RG: Menhaden-fish oil in a vitamin E-deficient diet: protection against chloroquineresistant malaria in mice. Am J Clin Nutr 1989;50:1237-1239.

144 Levander OA, Ager AL Jr, Morris VC, May RG: Plasmodium yoelii: comparative antimalarial activities of dietary fish oils and fish oil concentrates in vitamin E-deficient mice. Exp Parasitol 1990;70:323-329.

145 Fevang P, Saav H, Hostmark AT: Dietary fish oils and long-term malaria protection in mice. Lipids 1995;30:437-441.

146 Godfrey DG: Antiparasitic action of dietary cod liver oil upon Plasmodium berghei and its reversal by vitamin E. Exp Parasitol 1957;6:555-565.

147 Edirisinghe JS: Infections in the malnourished: with special reference to malaria and malnutrition in the tropics. Ann Trop Paediatr 1986;6:233-237.

148 Davis TM, Binh TQ, Danh PT, et al: Serum vitamin $\mathrm{A}$ and $\mathrm{E}$ concentrations in acute falciparum malaria: modulators or markers of severity? Clin Sci 1994;87:505-511.

149 Eaton JW, Eckman JR, Berger E, Jacob HS: Suppression of malaria infection by oxidant-sensitive host erythrocytes. Nature 1976;264:758-760.

150 Clark IA, Hunt NH: Evidence for reactive oxygen intermediates causing hemolysis and parasite death in malaria. Infect Immun 1983;39:1-6.

151 Wozencraft AO, Dockrell H, Tarvern J, et al: Killing of human malaria parasites by macrophage secretory products. Infect Immun 1984;43:664-669.

152 Adelekan DA, Adeodu OO, Thurnham DI Comparative effects of malaria and malnutrition on plasma concentrations of antioxidant micronutrients in children. Ann Trop Paediatr 1997;17:223-227.

153 Gilbert DN, Moellering RC, Eliopoulos GM, Sande MA: The Sanford Guide to Antimicrobial Therapy, ed 36. Sperryville, Antimicrobial Therapy, 2007. 